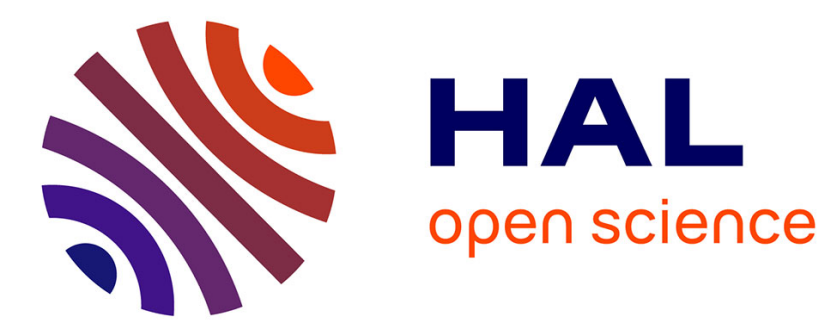

\title{
Pyridine Elaboration through Organometallic Intermediates: Regiochemical Control and Completeness
}

\author{
Manfred Schlosser, Florence Mongin
}

\section{To cite this version:}

Manfred Schlosser, Florence Mongin. Pyridine Elaboration through Organometallic Intermediates: Regiochemical Control and Completeness. Chemical Society Reviews, 2007, 36, pp.1161-1172. 10.1039/b706241a . hal-01002816

\section{HAL Id: hal-01002816 https://hal.science/hal-01002816}

Submitted on 6 Jun 2014

HAL is a multi-disciplinary open access archive for the deposit and dissemination of scientific research documents, whether they are published or not. The documents may come from teaching and research institutions in France or abroad, or from public or private research centers.
L'archive ouverte pluridisciplinaire HAL, est destinée au dépôt et à la diffusion de documents scientifiques de niveau recherche, publiés ou non, émanant des établissements d'enseignement et de recherche français ou étrangers, des laboratoires publics ou privés. 


\title{
Pyridine Elaboration through Organometallic Intermediates: Regiochemical Control and Completeness
}

\author{
Manfred Schlosser $^{*[a]}$ and Florence Mongin ${ }^{[b]}$
}

Pyridines carrying heterosubstituents (such as carboxy, amido, amino, alkoxy or trifluoromethyl groups or solely individual halogen atoms) can be readily and site selectively metalated. Subsequent reaction with a suitable electrophile opens rational access to a wealth of new building blocks for the synthesis of biologically active compounds. This approach relies on organometallic methods, which are both efficacious and extremely flexible as far as the substitution site and the product structure are concerned.

Key Words: Pyridine • Metalation • Heterosubstituents • Electrophiles • Lithium Compounds $\bullet$ Superbase Chemistry

\section{Introduction}

Pyridines belong to the most prominent and most important heterocycles. Derivatives such as nicotine, nicotinamide (niacin) and nicotinamide adenine dinucleotide diphosphate (NADP) or pyridoxine (vitamin $\mathrm{B}_{6}$ ) occupy biological key positions. In addition, countless pyridine congeners are registered as pharmaceutically or agriculturally active principles. In general, a fair degree of structural complexity characterizes such compounds. This calls for highly selective, flexible and efficacious methods of synthesis.

[a] Institute of Chemical Sciences and Engineering (ISIC)

Ecole Polytechnique Fédérale, BCh

CH-1015 Lausanne, Switzerland

e-mail : manfred.schlosser@epfl.ch

fax: ++41-21-6939365

[b] Synthèse et Electrosynthèse organiques

Université de Rennes 1, CNRS

Bâtiment 10A, Case 1003, Campus scientifique de Beaulieu

F-35042 Rennes, France

e-mail : florence.mongin@univ-rennes1.fr

fax : +33-2-23-23-69-55 
Pyridine itself can be extracted from coal tar or made by condensation of crotonaldehyde and formaldehyde with ammonia in the presence of air. ${ }^{[1]}$ It undergoes electrophilic substitutions such as nitration, sulfonation and halogenation exclusively at the 3 -position. ${ }^{[1]} 3$ Bromopyridine can be converted into 3-acetonylpyridine by a single electron-transfer mediated reaction with the potassium enolate of acetone in liquid ammonia and into 3aminopyridine using ammonia in the presence of copper sulfate at elevated temperatures. ${ }^{[1]}$ Halogen atoms located at the 2- or 4-position are readily displaced by all kinds of nucleophiles under mild conditions and without requiring transition element assistance. ${ }^{[1]}$ Pyridine reacts with sodium or potassium amide to afford 2-aminopyridine (Tchitchibabin process) and with organometallics such as butyllithium or phenyllithium to give the corresponding 2-alkyl- or 2-arylpyridine after metal hydride elimination or direct oxidation. ${ }^{[1,2]}$ In contrast, Grignard reagents add at the position of $N$-silylated pyridines. ${ }^{[3]}$

There is a trick to reorient electrophilic substitution from the ordinary 3-position also to the 4-position. As long as unprotonated, pyridine $N$-oxides accommodate the reagent cleanly at the $N$-remote site. ${ }^{[4]}$ Catalytic hydrogenation smoothly reduces the resulting 4-nitropyridine $N$-oxide to 4 -aminopyridine. ${ }^{[5]}$ The same conditions can be applied to convert 3-nitropyridine to 3-aminopyridine. Conversely, 2-nitropyridine is prepared from the directly accessible 2aminopyridine by treatment with peroxosulfuric acid. ${ }^{[6]}$ All three aminopyridines (Scheme 1) can be further transformed in many ways, in particular through to corresponding diazonium salts.

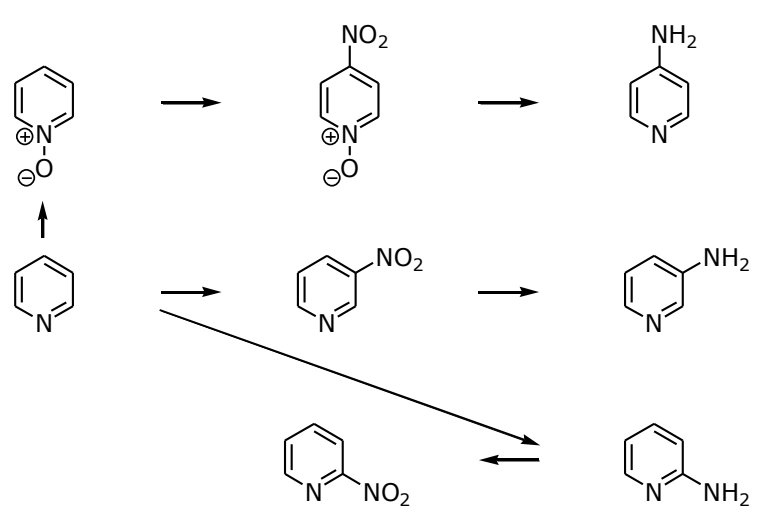

Scheme 1. The three aminopyridines derived directly or indirectly from the parent compounds.

Problems arise as soon as a second substituent has to be attached to the pyridine nucleus. Regioisomeric mixtures will be obtained almost inevitably. Sometimes the selectivity is still amazingly high. For example, 3-methoxypyridine provides a $10: 1$ mixture of 2- and 6nitration products and no 4 - or 5-isomers at all (Scheme 2). ${ }^{[7]}$ More typically, however, product mixtures result that are worthless in practical terms. Thus, 2-aminopyridine gives rise 
to half a dozen of mono-, di- and tribrominated derivatives when treated with elemental bromine in solution or in the gas phase (Scheme 3$){ }^{[8]}$

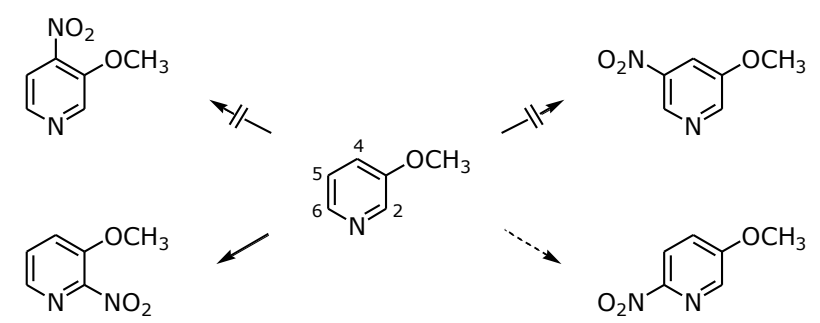

Scheme 2. The not perfectly regioselective nitration of 3-methoxypyridine.

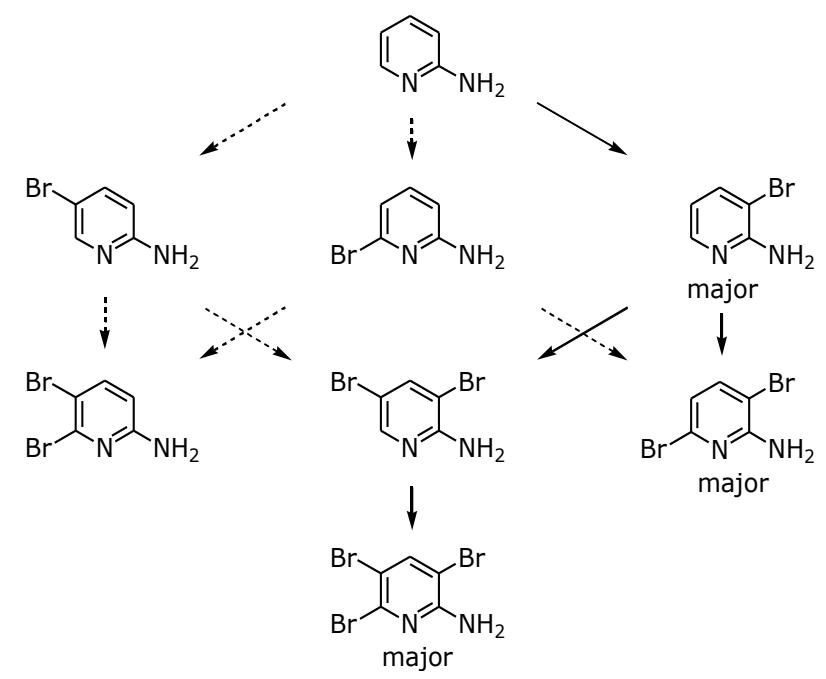

Scheme 3. Mono-, di- and tribrominated derivatives formed upon bromination of 2aminopyridine.

Site selectivity could be easily achieved of course if the electrophile would be allowed to react with a specific metal-bearing pyridine rather than with the unmodified heterocycle having several vacant and hence potentially eligible positions. Pyridylmagnesium halides (Scheme 4) and pyridyllithiums (Scheme 4) are readily generated by the reductive insertion of a metal (such as magnesium) ${ }^{[9]}$ into the carbon-halogen bond of a given bromopyridine or by permutational halogen/metal interconversion of the latter with isopropylmagnesium chloride ${ }^{[10]}$ or butyllithium. ${ }^{[1]}$ Dibromopyridines could serve as particularly attractive starting materials as they offer the possibility to replace one halogen by a first electrophile and the other one by a second electrophile. Unfortunately, this approach suffers from serious drawbacks. First of all, halogens of the same kind can be alternatively and selectively exchanged against metal only in exceptional cases, so far just in 2,5-dibromopyridine and 2,3,5-tribromopyridine (Scheme 4). ${ }^{[12]}$ Ordinarily, the two halogen atoms (as present, e.g., in 
3,4-dibromopyridine) are attacked randomly. Moreover, the use of dibromopyridines as key starting materials would only defer the problem as their regioselective preparation is in general not trivial. Finally, unexpected complications may be encountered. Thus, the exchange by-product 1-bromobutane may react, even unnoticed by the authors, ${ }^{[13]}$ with the newly generated organometallic intermediate.

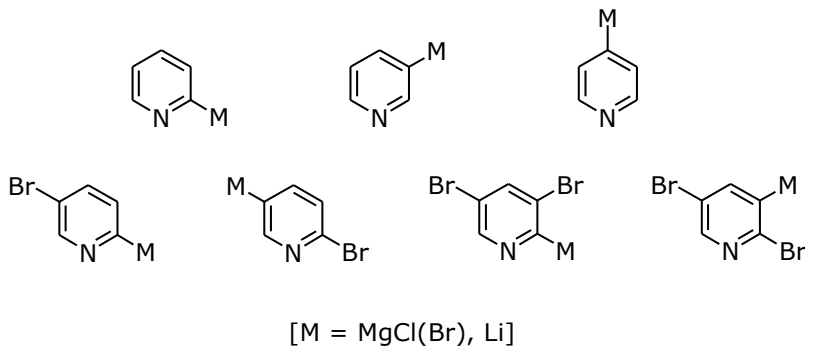

Scheme 4. Site specifically activated pyridines by bromine/magnesium or bromine/lithium exchange (reductive insertion or permutational interconversion): 2-, 3- and 4-pyridylmetals and bromopyridylmetals.

The lesson to be drawn from this dilemna is simple: maintain the organometallic route as a guiding principle for the electrophilic substitution of heterocycles but introduce the metal by metalation (i.e., hydrogen/metal permutation) rather than by halogen/metal exchange (be it insertion or permutation). The metalation and subsequent substitution, in particular functionalization of a variety of pyridines will be extensively reviewed in the following Sections. To resume already now, the metalation of pyridine itself or its alkyl- or aryl-bearing congeners is not very tempting under a synthesis point of view but is a highly appealing option if the metalation is assisted and oriented by electronegative substituents.

\section{Metalation}

\subsection{Pyridine and Picolines}

Brandsma et al. ${ }^{[14]}$ have reported the metalation of pyridine using our superbasic LIC$\mathrm{KOR}^{[15,16]}$ mixture (LIC = butyllithium, plus $\mathrm{KOR}=$ potassium tert-butoxide) as the reagent. The observed blue color, the moderate yields and notably the found product composition of 2-, 3- and 4-isomers raise doubts about the assumed deprotonation process and argue rather for a single electron-transfer (SET) mechanism. The latter is definitively operative when pyridine is treated by lithium diisopropylamide (LIDA) in diethyl ether (DEE) and in the presence of hexamethylphosphoric triamide (HMPT) as evidenced by the formation of 2,2'bipyridine in $50 \%$ yield. ${ }^{[17]}$ On the other hand, deprotonation can be brought about when 
facilitated by coordinative neighboring group assistance. When treated, under in situ trapping conditions, simultaneously with lithium 2,2,6,6-tetramethylpiperidide (LITMP) and tributylchlorostannane in tetrahydrofuran (THF), 2,2'-bipyridyl gives via the intermediates 1 and 2 the mono-3- and di-3,3'-stannylated derivatives in 50\% and 14\% yield, respectively. In the same way, 2,4'-bipyridyl can be converted via the species 3 into the 2 -stannane in $64 \%$ yield (Scheme 5). ${ }^{[18]}$

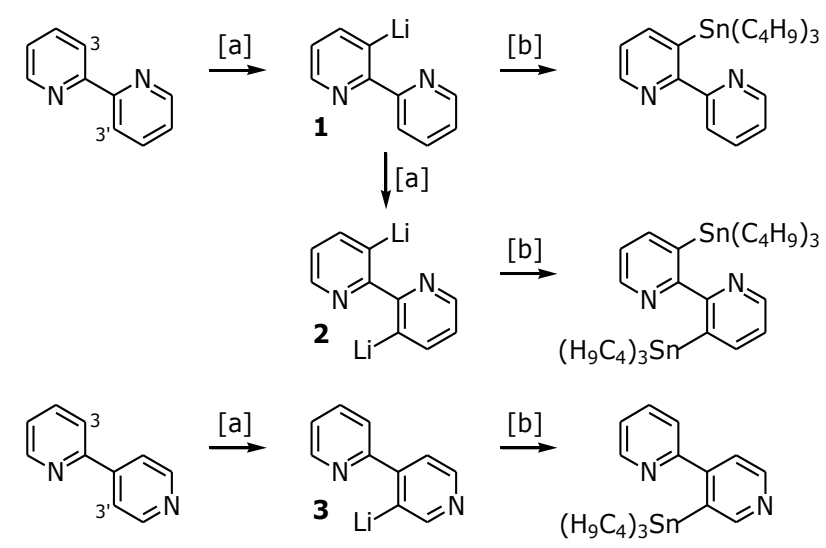

Scheme 5. Deprotonation of $2,2^{\prime}-$ and $2,4^{\prime}-$ bipyridyl with LITMP and in situ trapping of the intermediates $\mathbf{1}-\mathbf{3}$ with tributylchlorostannane. Reaction conditions: [a] LITMP in THF at -70 ${ }^{\circ} \mathrm{C}$ and in the presence of $[\mathrm{b}]$ tributylchlorostannane.

Coordination of lithium to the ring nitrogen atom is without doubt also at the origin of the remarkable selectivity of Caubère's base ${ }^{[19]}$ the $1: 1$ mixture of butyllithium with lithium 2(dimethylamino)ethoxide (LIDMAE), toward pyridines. To favor complexation, the reaction is generally conducted in hexanes, but also DEE and THF can be employed. Pyridine, ${ }^{[19 c]} 4-$ methylpyridine $(\gamma$-picoline $)$ and 3,5-dimethylpyridine $\left(\beta, \beta^{\prime} \text {-lutidine }\right)^{[19 f]}$ are metalated exclusively at the 2-position generating intermediates 4 (Scheme 6).

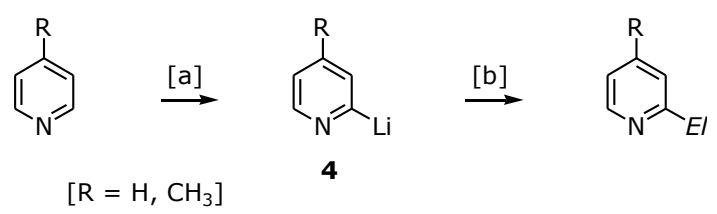

Scheme 6. Selective metalation of pyridine and 4-methylpyridine using Caubère's base. Reaction conditions: [a] $\mathrm{LiC}_{4} \mathrm{H}_{9}+\mathrm{LiOCH}_{2} \mathrm{CH}_{2} \mathrm{~N}\left(\mathrm{CH}_{3}\right)_{2}$. [b] $\mathrm{El}-\mathrm{X}=\mathrm{ICH}_{3}, \mathrm{ClSi}\left(\mathrm{CH}_{3}\right)_{3}, \mathrm{H}_{3} \mathrm{CS}-\mathrm{SCH}_{3}, \mathrm{H}_{5} \mathrm{C}_{6}$ $\mathrm{CH}=\mathrm{O},\left(\mathrm{H}_{2} \mathrm{C}\right)_{5} \mathrm{C}=\mathrm{O},\left(\mathrm{H}_{3} \mathrm{C}\right)_{2} \mathrm{~N}-\mathrm{CH}=\mathrm{O}$, etc.

Despite this impressive record, Caubère's base does nevertheless not always behave regioselectively. For example, 3,4-dimethylpyridine ( $\beta, \gamma$-lutidine) undergoes lithiation 
concomitantly at the 2- and 6-position and at the 4-methyl group as well (in a $78: 5: 17$ ratio). ${ }^{[19 \mathrm{~h}]}$ Moreover, the reagent has to be used in large excess (3- to 20-fold) which inevitably consumes large amounts of the electrophile and limits the scale (to $1-5 \mathrm{mmol}$ of substrate in most cases). Under such circumstances alternative possibilities should be kept in mind. They are briefly outlined in the next Section.

\subsection{Pyridine Oxides and Pyridine Borates}

As a systematic investigation has revealed, ${ }^{[20]}$ pyridine $N$-oxides are selectively metalated at the 2-position (intermediates 5, Scheme 7). Unfortunately the yields are poor (14 - 44\%). Disubstituted derivatives rank among the most abundant by-products.

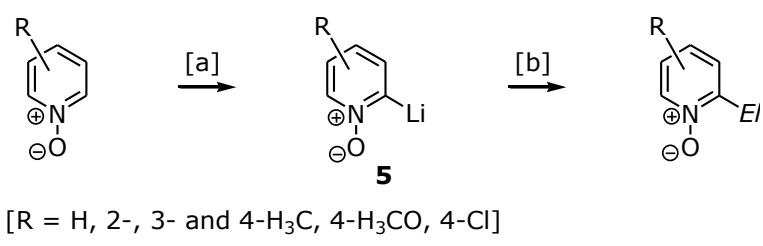

Scheme 7. Metalation of pyridine $N$-oxides. Reaction conditions: [a] $\mathrm{LiC}_{4} \mathrm{H}_{9}$ (in $\mathrm{DEE}$ or $\mathrm{THF}) ;[\mathrm{b}] E l-\mathrm{X}=\mathrm{CO}_{2},\left(\mathrm{H}_{5} \mathrm{C}_{6}\right)_{2} \mathrm{C}=\mathrm{O},\left(\mathrm{H}_{2} \mathrm{C}\right)_{5} \mathrm{C}=\mathrm{O}$.

$\beta$-Oxidopyridinium betaines also are amenable to lithiation at the 2-position (intermediates 6, Scheme 8). ${ }^{[21]}$ The zwitterionic substrates form readily when the pyridine and hexafluoroacetone are combined.

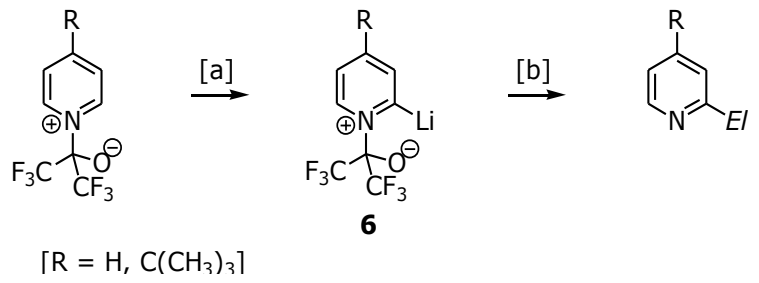

Scheme 8. Metalation of pyridine/hexafluoroacetone adducts. Reaction conditions: [a] LITMP in THF at $-107{ }^{\circ} \mathrm{C}$; [b] $E l-\mathrm{X}=\mathrm{H}_{5} \mathrm{C}_{6}$ $\mathrm{CH}=\mathrm{O},\left(\mathrm{F}_{3} \mathrm{C}\right)_{2} \mathrm{C}=\mathrm{O}, \mathrm{I}_{2}, \mathrm{ClSi}\left(\mathrm{CH}_{3}\right)_{3}$.

Intermediates 5 and $\mathbf{6}$ suggest a coordinative interaction between the oxido anion and lithium. However, mere electrostatic effects suffice to activate the 2-position toward proton abstraction accomplished with strong bases as evidenced by the behavior of pyridine, ${ }^{[22]} 4$ methylpyridine $^{[22]}$ and 4-(dimethylamino)pyridine $e^{[23]}$ adducts with boron trifluoride (intermediates 7, Scheme 9). 


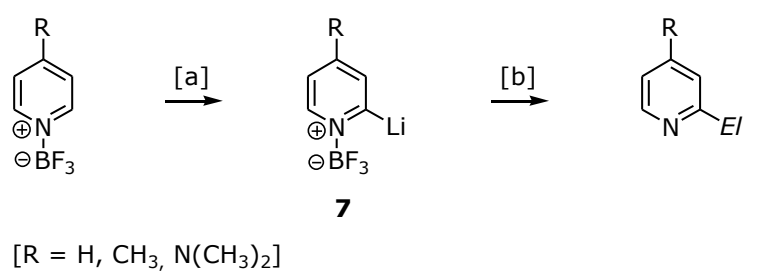

Scheme 9. Metalation of pyridine/boron trifluoride adducts. Reaction conditions: [a] LITMP in DEE at $-75{ }^{\circ} \mathrm{C}$; [b] $E l-\mathrm{X}=\mathrm{H}_{5} \mathrm{C}_{6^{-}}$ $\mathrm{CH}=\mathrm{O},\left(\mathrm{H}_{5} \mathrm{C}_{6}\right)_{2} \mathrm{C}=\mathrm{O},\left(\mathrm{CH}_{2}\right)_{5} \mathrm{C}=\mathrm{O}$.

The potential of the latter method is far from being explored and exploited. In the absence of boron trifluoride, $\gamma$-picoline is deprotonated at the methyl group. The scope of lithium ditert-butyl-2,2,6,6-tetramethylpiperid-1-ylzincate for the lithiation of heterocycles at $\mathrm{N}$ adjacent sites, so far demonstrated with pyridine, quinoline and isoquinoline on a quasi-

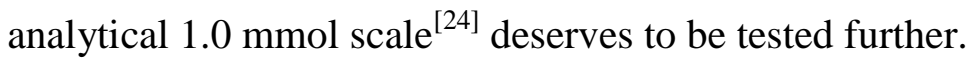

\subsection{Pyridinecarboxylic Acids and Congeners}

Both ethyl pyridine-3- and -4-carboxylate were found to be very prone to proton abstraction by lithium diisopropylamine at the 4- and 2-position, respectively. However, the lithiated species proved unstable, being lost by instantaneous autocondensation. ${ }^{[25]}$ Such problems can be circumvented when pyridinecarboxylic acids themselves or halogenated derivatives thereof are treated with two molar equivalents of LITMP in THF at $-75^{\circ} \mathrm{C}$ or -50 ${ }^{\circ} \mathrm{C} .{ }^{[26]}$ The thus generated intermediates 8 and 9 (Scheme 10) can be effectively trapped by a variety of electrophiles.

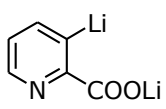

$8 \mathbf{a}$<smiles>O=C(O)c1c(Cl)ccnc1Cl</smiles>

9 a<smiles>O=C(O)c1cnccc1I</smiles>

8b<smiles>O=C(O)c1cnc(Cl)cc1Cl</smiles>

9b<smiles>O=C(O)c1cccnc1</smiles>

8c<smiles>O=C(O)c1cncc(Br)c1Cl</smiles>

9c

Scheme 10. Organolithium species generated by treatment of pyridine-2-, -3- and -4-carboxylic acid, 2- and 6-chloropyridine-3-carboxylic acid and 5-bromopyridine-3-carboxylic acid with LITMP (2 equiv.). 
Abstraction of a "mobile proton", this time from an NH entity, precedes also the neighboring group assisted metalation of secondary pyridinecarboxamides (e.g., intermediates 10 and 11, Scheme 11 ${ }^{[27]}$ which occurs analogously as established in the benzene series. ${ }^{[28]}$

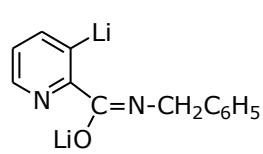

10

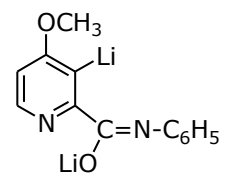

$11 \mathrm{a}$

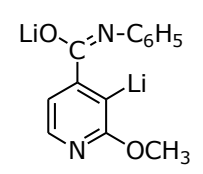

$11 \mathbf{b}$

Scheme 11. 3-Lithiated $N$-benzyl or $N$-phenyl pyridinecarboxamides.

Although in the benzene series sec-butyllithium is required, ${ }^{[29]}$ tertiary pyridinecarboxamides undergo smooth deprotonation at a vacant 3- or 4-position even with LIDA as the base (intermediates 12 and 13, Scheme 12). ${ }^{[30]}$ The $N$-substituents are generally isopropyl groups but also ethyl groups are appropriate.

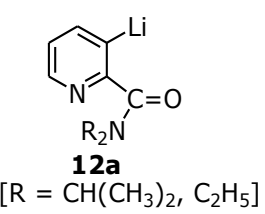

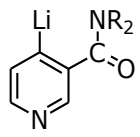

12b

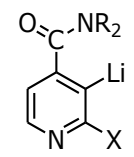

12c: $\mathrm{X}=\mathrm{H}$

13: $\mathrm{X}=\mathrm{OCH}_{3}$

Scheme 12. 3- or 4-Lithiated $N, N$-diisopropyl (or $N, N$-diethyl) pyridine-2-, $\quad-3-$ or $-4-$ carboxamides.

Oxazolines are imino-ethers incorporated into a ring structure and hence are masked carboxylic acids, which are immediately formed upon acidic hydrolysis. Following precedents encountered in the benzene ${ }^{[31 \mathrm{a}]}$ and thiophene series, ${ }^{[31 \mathrm{~b}]} 3$ - and 4-(4,5-dihydro-4,4dimethyloxazol-2-yl)pyridines are readily metalated at the 4- and 3-position, respectively (intermediates $\mathbf{1 3}$ and 14, Scheme 13). ${ }^{[32]}$ It is advisable to employ relatively weak bases such as methyllithium or LITMP as most organomagnesiums or organolithiums tend to add nucleophilically to the 4-position.

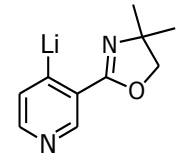

$13 a$

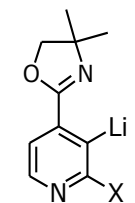

13b: $X=\mathrm{H}$

14: $X=\mathrm{OCH}_{3}$

Scheme 13. 4- or 3-Lithiated 3- and 4-(4,5dihydro-4,4-dimethyloxazol-2-yl)pyridines. 


\subsection{Amino- and Amido-Substituted Pyridines}

Guided once more by leads existing in the benzene series, ${ }^{[33]} \mathrm{N}$-pivaloyl ${ }^{[34]}$ or $\mathrm{N}$-tertbutoxycarbonyl $^{[35]}$ protected 2-, 3- and 4-aminopyridines have been effectively metalated using butyllithium or tert-butyllithium (intermediates $\mathbf{1 5}-\mathbf{1 8}$, Scheme 14). The organometallic species produced in this way open an easy access to a variety of valuable, biologically active compounds.

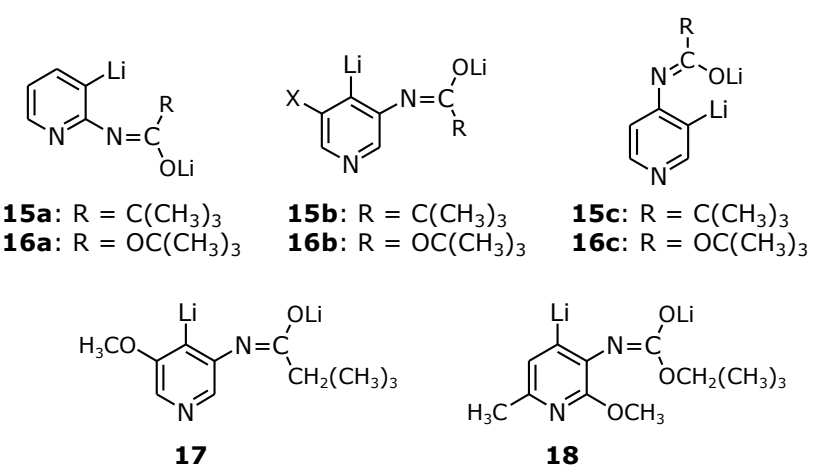

Scheme 14. 3- or 4-Lithiated $N$-pivaloyl or $N$ tert-butoxycarbonyl protected 2-, 3- and 4aminopyridines.

The metalation of ( $N, N$-dialkylamino)alkyl substituted pyridines has been only scarcely examined up to now. Both 2- and 4-(dimethylamino)pyridine ${ }^{[19 \mathrm{~g}]}$ and 3-(N-methylpyrrolidin2-yl)pyridine (nicotine) ${ }^{[36 a]}$ were found to be attacked by an excess of Caubère's base in hexanes exclusively at the 6-position, whereas lithiation of 6-chloronicotine with butyllithium occurred cleanly at the 5-position ${ }^{[36 b]}$ (intermediates $\mathbf{1 9}$ and 20, Scheme 15).

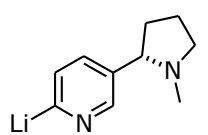

19

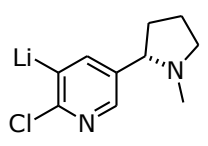

20

Scheme 15. Metalation of nicotine and 6chloronicotine at the 6- and 5-position, respectively.

\subsection{Hydroxy-and Alkoxy-Substituted Pyridines}

Methoxypyridines and other alkoxypyridines are readily metalated by lithium dialkylamides such as LIDA or LTMP and by aryllithiums such as mesityllithium or phenyllithium (intermediates 21 - 24, Scheme 16). ${ }^{[37]}$ Caubère's base promotes the metalation 
of 4-methoxypyridine at the 3-position. ${ }^{[19 \mathrm{~g}]}$ Neat alkyllithiums, in particular butyllithium, tend to add nucleophilically at the 2- or 6-position, a sometimes quantitative process. ${ }^{[19 b, 37 b, 38]}$

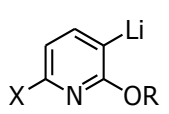

21a: $X=\mathrm{H}$

22: $X=\mathrm{H}_{3} \mathrm{CO}$

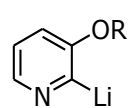

$\left[\mathrm{OR}=\mathrm{OCH}_{3}, \stackrel{\mathbf{2 1} \mathbf{b}}{\mathrm{OC}_{2}} \mathrm{H}_{5}, \mathrm{OCH}_{2} \mathrm{C}_{6} \mathrm{H}_{5}\right]$

24<smiles>COCc1cnccc1Cl</smiles>

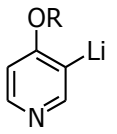

21c

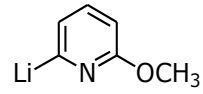

23

Scheme 16. Lithiated alkoxypyridines.

Two remarkable optional site selectivities deserve attention. As mentioned in the preceding paragraph, 2-methoxypyridine is attacked by lithium amides or aryllithiums exclusively at the 3 -position, ${ }^{[37 \mathrm{a}, \mathrm{b}, \mathrm{e}]}$ but by Caubère's base solely at the 6-position. ${ }^{[19 c]} 3$ Ethoxy and 3-methoxypyridine get deprotonated, respectively, by LIDA and by Caubère's base $^{[19 \mathrm{~g}]}$ at the 2-position ${ }^{[37 \mathrm{a}]}$ whereas 3-(methoxymethoxy)pyridine reacts at the more acidic 4-position. ${ }^{[39]}$

$O$-Lithiated hemiaminals can be easily formed by nucleophilic addition of either an organolithium to a dialkylformamide or of a lithium dialkylamide to a carbaldehyde. As first demonstrated by H.W. Gschwend et al., ${ }^{[40]}$ the lithium $\alpha$-dialkylaminomethoxide unit provides neighboring group assistance to the metalation of adjacent aromatic positions. In the intramolecular competition with a methoxy group, the chelating $\mathrm{N}$-(2-dimethylaminoethyl)- $\mathrm{N}$ methylamino chain proves to be a superior and the less flexible $N^{\prime}$-methyl- $N$-piperidazyl ring an inferior ortho-directing substituent. They give rise to the intermediates $\mathbf{2 4 a}$ and $\mathbf{2 4 b}$, respectively (Scheme 17). ${ }^{[1]}$

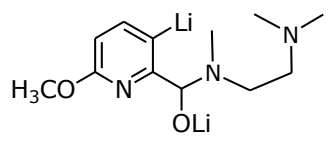

24a

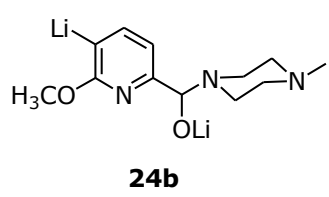

24b

Scheme 17. $C$-Lithiated lithium $\alpha$-(6-methoxypyridyl)- $\alpha$-(dialkylaminomethoxides.

\subsection{Halo- and Trifluoromethyl-Substituted Pyridines}

The metalation of halopyridines was pioneered by G. W. Gribble et al. ${ }^{[42]}$ Using LIDA as the base, 2-bromopyrid-3-yllithium, ${ }^{[43 b]}$ 3-bromopyrid-4-yllithium, ${ }^{[42,43 a]}$ 4-bromopyrid-4- 
yllithium $^{[43 c]}$ and 3,5-dibromopyrid-4-yllithium ${ }^{[44]}$ have been made accessible. All these intermediates $\left(\mathbf{2 5}-\mathbf{2 6}\right.$, Scheme 18) are fairly stable in THF at $-100{ }^{\circ} \mathrm{C}$.

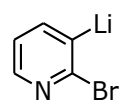

$25 a$

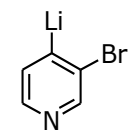

25b<smiles>Clc1c(Br)cncc1Br</smiles>

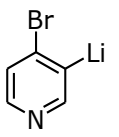

25c

Scheme 18. Lithiated bromopyridines.

Some of the reported regiohomogenities have to be met with caution, however. As a careful reexamination has revealed, ${ }^{[45]}$ species $\mathbf{2 5 a}$ is contaminated by the isomeric 2bromopyrid-4-yllithium in an approximate 9:1 ratio. Traces of 3-bromopyrid-2-yllithium are still produced at $-100{ }^{\circ} \mathrm{C}$ along with 3-bromopyrid-4-yllithium and the amount of undesired compounds increases at higher temperatures.

2-Chloropyrid-3-yllithium (27a), 3-chloropyrid-4-yllithium (27c) and 4-chloropyrid-3yllithium (27d) are readily generated when the corresponding chloropyridines are treated with $\mathrm{LIDA}^{[42]}$ (Scheme 19). In contrast, when butyllithium in the presence of $N, N, N^{\prime}, N^{\prime}$ tetramethylethylenediamine (TMEDA) ${ }^{[43 a]}$ or Caubère's base ${ }^{[46]}$ is employed, 3-chloropyridine gives, respectively, mainly or exclusively 3-chloropyrid-2-yllithium (27b). 4-Chloropyridine undergoes lithiation at the 2-position (intermediate 27e) when Caubère's base is employed in hexane at $-75^{\circ} \mathrm{C} .{ }^{[19 \mathrm{~g}]}$<smiles>Clc1cccnc1Cl</smiles>

$27 a$<smiles>Clc1cccnc1Cl</smiles>

27b<smiles>Clc1ccncc1Cl</smiles>

27c<smiles>Clc1ccncc1I</smiles>

27d

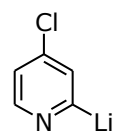

27e

Scheme 19. Lithiated monochloropyridines.

Optional site selectivity ${ }^{[12,47]}$ of metalation is characteristic for several dichloropyridines. Whatever the base, $2,3-,^{[48]} 2,4-{ }^{[49]}$ and $3,5-{ }^{[50]}$ dichloropyridine are only deprotonated at the 3 and 4- position (intermediates 28, Scheme 20).

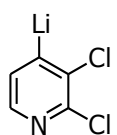

$28 a$<smiles>Clc1ccnc(Cl)c1Cl</smiles>

28b<smiles>Clc1cncc(Cl)c1Cl</smiles>

28c 
Scheme 20. Site-immutable metalation of three dichloropyridines.

However, 2,6-dichloropyridine affords 2,6-dichloropyrid-3-yllithium (29a) and 2,6dichloropyrid-4-yllithium (29b) in a $10: 1$ or $1: 3$ ratio depending on whether LIDA or butyllithium serves as the base ${ }^{[51]}$ (Scheme 21). 2,5-Dichloropyridine reacts cleanly with tertbutyllithium at the 6-position and with the butyllithium/TMEDA complex at the 4-position (intermediates 30, Scheme 20). 3,4-Dichloropyridine undergoes selective metalation with LITMP in DEE at the 2-position and with LIDA in THF at the 5-position (intermediates 31, Scheme 21).

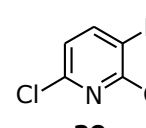

29a<smiles>Clc1ccc(Cl)c(I)n1</smiles>

$30 a$<smiles>Clc1ccnc(Cl)c1Cl</smiles>

31a<smiles>Clc1cccc(Cl)n1</smiles>

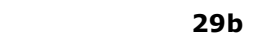<smiles>C1CCCCC1</smiles><smiles>Clc1ccc(Cl)nc1</smiles><smiles>C1CCCC1</smiles><smiles>Clc1ccncc1Cl</smiles><smiles></smiles><smiles>Clc1ccnc(Cl)c1</smiles><smiles>Clc1cncc(Cl)c1Cl</smiles>

Scheme 21. Optional site selectivity in the metalation of 2,6-, 2,5- and 3,4-dichloropyridine.

Low temperature protocols should equally enable the generation and subsequent transformation of tri- and tetrachloropyridyllithiums. The only example of that kind known so far is 2,3,6-trichloropyrid-4-yllithium. ${ }^{[52]}$

2-Fluoropyridine ${ }^{[42,53]}$ and 4-fluoropyridine ${ }^{[54]}$ are readily metalated at the 3-position (intermediates 32a and 32d, Scheme 22). Deprotonation of 3-fluoropyridine ${ }^{[55]}$ occurs cleanly at the most acidic 4-position after long exposure times and in relative basic media whereas the 2-position is favored when neighboring group assistance by coordination to the ring nitrogen atom is effective. Thus, TMEDA-activated butyllithium metalates 3-fluoropyridine solely at the 4-position when applied in THF, but mainly at the 2-position when in $\mathrm{DEE}^{[55]}$ (intermediates 32c and 32b, respectively, Scheme 22). When TMEDA is replaced by the nonchelating 1,8-diazabicyclo[2.2.2] octane (DABCO), the 2-position is exclusively attacked in DEE. ${ }^{[55 c]}$ 
<smiles>Fc1ncccc1Cl</smiles>

$32 \mathrm{a}$

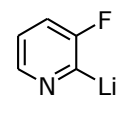

32b<smiles>Fc1cnccc1Cl</smiles>

32c<smiles>Fc1ccncc1I</smiles>

32d

Scheme 22. Selective metalation of 2-, 3- and 4fluoropyridine.

2-Fluoropyridine has four different vacant positions. To illustrate the concept of "regiochemically exhaustive substitution", ${ }^{[12,56]}$ the carboxy group was introduced into each of these empty sites passing through the organometallic intermediates $\mathbf{3 2 a}$ and $\mathbf{3 3 a}-\mathbf{3 3} \mathbf{c}^{[57]}$ (Scheme 23). The execution relies on our "toolbox methods" ${ }^{[12]}$ and, more precisely, the clever use of two favorite protective groups. Bulky trialkylsilyl entities do not only impede the access of any reagent to the site they occupy themselves but also screen sterically the directly adjacent positions. Thus, 3-chloro-2-fluoro-4-(trimethylsilyl)pyridine can only be deprotonated at the 6-position. In contrast, the protective chlorine substituent eliminates the 3-position as an acidic site but, at the same time, activates the adjacent 4-position. In this way, a trimethylsilyl group or a second chlorine atom can be readily introduced there to deflect the metalation to the 6- and 5-position, respectively. ${ }^{[57]}$ After quenching of the intermediates with the desired electrophile, the protective groups can be conveniently removed by protodesilylation or reduction (Scheme 23).

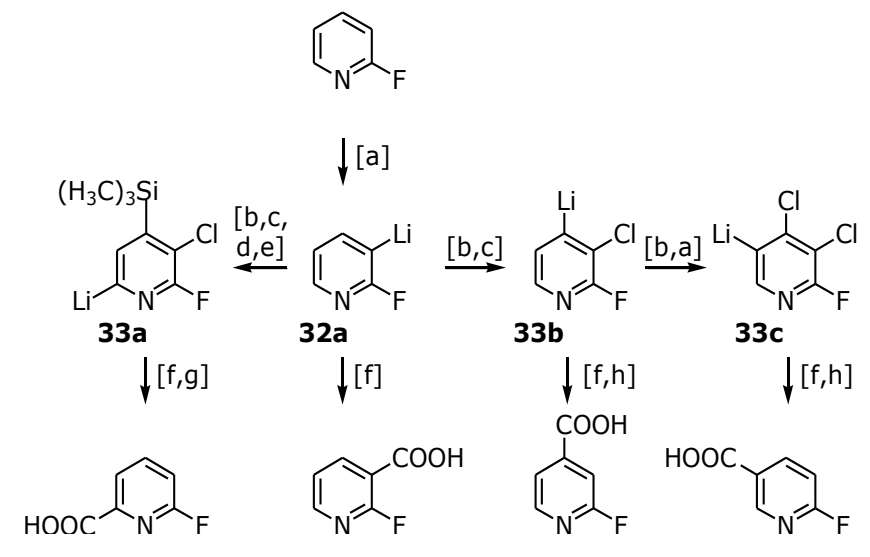

Scheme 23. Regiochemically exhaustive functionalization of 2-fluoropyridine. Reaction conditions: [a] LIDA in THF at $-75^{\circ} \mathrm{C}$; [b] $\mathrm{Cl}_{2} \mathrm{FCCClF}_{2}$; [c] $\mathrm{LiC}_{4} \mathrm{H}_{9}$ in $\mathrm{THF}$ at $-75^{\circ} \mathrm{C}$; [d] $\mathrm{ClSi}\left(\mathrm{CH}_{3}\right)_{3}$; [e] Excess $\mathrm{LiC}_{4} \mathrm{H}_{9} \quad+$ $\mathrm{LiOCH}_{2} \mathrm{CH}_{2} \mathrm{~N}\left(\mathrm{CH}_{3}\right)_{2}$ in hexanes at $-75{ }^{\circ} \mathrm{C}$; [f] (1.) $\mathrm{CO}_{2}$, (2.) aq. $\mathrm{HCl} ;[\mathrm{g}]\left(\mathrm{H}_{9} \mathrm{C}_{4}\right)_{4} \mathrm{NF}$ hydrate in $\mathrm{THF}$ at $+25{ }^{\circ} \mathrm{C}$; [h] $\mathrm{HCOONH}_{4}+$ cat. $\mathrm{Pd} / \mathrm{C}$ in ethanol at $+25^{\circ} \mathrm{C}$ (stirred slurry). 
Analogously, 3-fluoropyridine was converted through the organometallic intermediates $32 \mathbf{c}$ and 34a - $\mathbf{c}$ into the 3-fluoropyridine-2-, -4-, -5- and -6-carboxylic acids ${ }^{[58]}$ (Scheme 24). Chlorine and trimethylsilyl groups play again a crucial role in directing the metal to the targeted spot. 4-Chloro-3-fluoropyridine features another impressive example of optionally site selective metalation. LIDA in THF deprotonates the 5-position, but LITMP in (poorly coordinating) DEE the 2-position. The latter outcome opens another entry to 3-fluoropyridine2-carboxylic acid. ${ }^{[58]}$

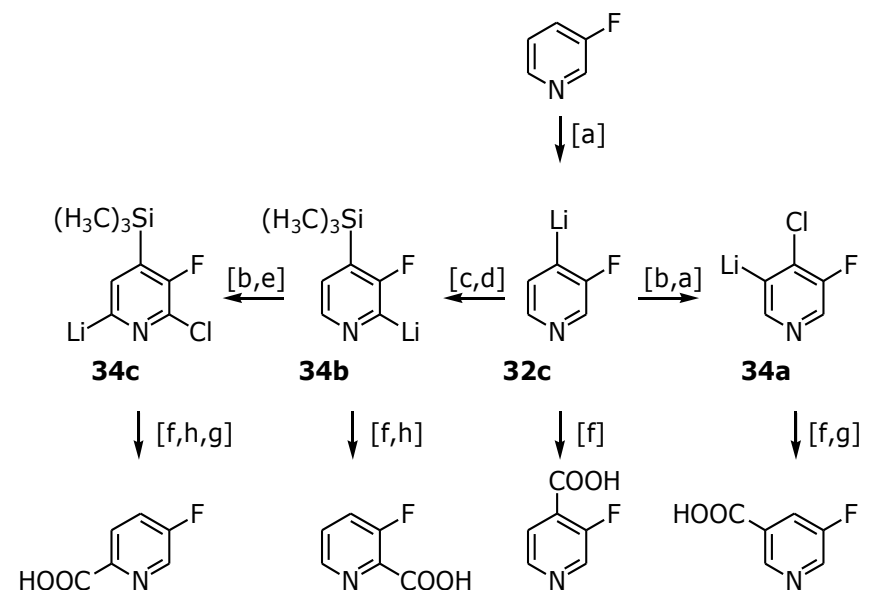

Scheme 24. Regiochemically exhaustive functionalization of 3-fluoropyridine. Reaction conditions: [a] LIDA in THF at $-75{ }^{\circ} \mathrm{C}$; [b] $\mathrm{Cl}_{2} \mathrm{FCCClF}_{2}$; [c] $\mathrm{ClSi}\left(\mathrm{CH}_{3}\right)_{3}$; [d] LITMP in THF at $-75 \quad{ }^{\circ} \mathrm{C} ; \quad[\mathrm{e}] \quad$ Excess $\mathrm{LiC}_{4} \mathrm{H}_{9}+$ $\mathrm{LiOCH}_{2} \mathrm{CH}_{2} \mathrm{~N}\left(\mathrm{CH}_{3}\right)_{2}$ in hexanes at $-75{ }^{\circ} \mathrm{C}$; [f] (1.) $\mathrm{CO}_{2}$, (2.) aq. $\mathrm{HCl} ;[\mathrm{g}] \mathrm{HCOONH}_{4}+$ cat. $\mathrm{Pd} / \mathrm{C}$ in methanol at $+50{ }^{\circ} \mathrm{C}$ (stirred slurry); [h] $\left(\mathrm{H}_{9} \mathrm{C}_{4}\right)_{4} \mathrm{NF}$ hydrate in $\mathrm{THF}$ at $+25^{\circ} \mathrm{C}$.

2,4-Difluoropyridine ${ }^{[59]}$ and 3,5-difluoropyridine ${ }^{[60]}$ undergo metalation of course at the location flanked by the two halogen atoms. 2,6-Difluoropyridine ${ }^{[61]}$ and 3,4difluoropyridine ${ }^{[62]}$ react with strong bases at, respectively, the 3- and 5-position, as expected.

The regioexhaustive functionalization of 2,3-difluoropyridine ${ }^{[63]}$ is once more tributary to the smart deployment of chlorine and trialkylsilyl protective groups followed by site-specific metalation (intermediates 35a - c, Scheme 24), carboxylation and ultimate "makeup take off". An alternative route to 5,6-difluoropyridine-3-carboxylic acid leads through 2,3-difluoro-4iodopyridine which is subjected to deprotonation-triggered heavy-halogen migration ${ }^{[14,64]}$ prior to neutralization, iodine/lithium permutation and reaction with carbon dioxide. ${ }^{[57]}$ 


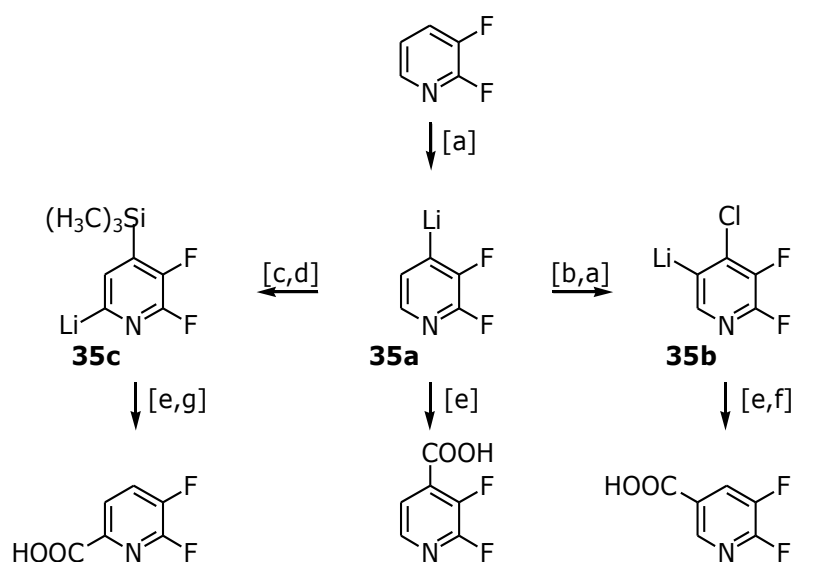

Scheme 25. Regiochemically exhaustive functionalization of 2,3-difluoropyridine. Reaction conditions: [a] LIDA in THF at $-75^{\circ} \mathrm{C}$; [b] $\mathrm{Cl}_{2} \mathrm{FCCClF}_{2}$; [c] $\mathrm{ClSi}\left(\mathrm{CH}_{3}\right)_{3}$; [d] Excess $\mathrm{LiC}_{4} \mathrm{H}_{9}+\mathrm{LiOCH}_{2} \mathrm{CH}_{2} \mathrm{~N}\left(\mathrm{CH}_{3}\right)_{2}$ in hexanes at -75 ${ }^{\circ} \mathrm{C}$; [e] (1.) $\mathrm{CO}_{2}$, (2.) aq. $\mathrm{HCl}$; [f] $\mathrm{HCOONH}_{4}+$ cat. $\mathrm{Pd} / \mathrm{C}$ in ethanol at $+25^{\circ} \mathrm{C}$ (stirred slurry); [g] $\left(\mathrm{H}_{9} \mathrm{C}_{4}\right)_{4} \mathrm{NF}$ hydrate in THF at $+25^{\circ} \mathrm{C}$.

The same principles can be applied to 2,5-difluoropyridine. ${ }^{[57]}$ The three possible carboxylic acids are obtained via the intermediates 36a - c, Scheme 26). The 3,6-difluoropyridinecarboxylic acid can be prepared either by exploiting the shielding effect of the trimethylsilyl group (Scheme 26) or also by taking advantage of the ambivalent reactivity of 4-chloro-2,5-difluoropyridine which undergoes metalation with the superbasic LIC-KOR mixture at the 3-position (as shown in Scheme 26), but with LITMP in diethyl ether (DEE) at the 6-position. ${ }^{[57]}$

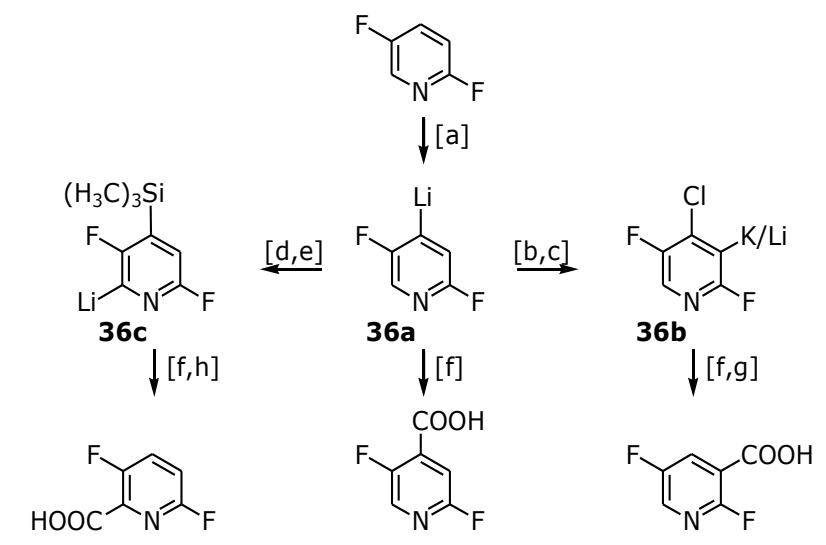

Scheme 26. Regiochemically exhaustive functionalization of 2,5-difluoropyridine. Reaction conditions: [a] LIDA in THF at $-75^{\circ} \mathrm{C}$; [b] $\mathrm{Cl}_{2} \mathrm{FCCClF}_{2}$; [c] LIDA + $N, N, N^{\prime}, N^{\prime \prime}, N^{\prime \prime}-$ pentamethyldiethylenetriamine (PMDTA) + $\mathrm{KOC}\left(\mathrm{CH}_{3}\right)_{3}$ in $\mathrm{THF}$ at $-75{ }^{\circ} \mathrm{C}$; [d] $\mathrm{ClSi}\left(\mathrm{CH}_{3}\right)_{3}$; [e] LITMP in DEE at $-75^{\circ} \mathrm{C}$; [f] (1.) $\mathrm{CO}_{2}$ (2.) aq. $\mathrm{HCl} ;$ [g] $\mathrm{Zn}$ (powder) in $25 \%$ aq. $\mathrm{NH}_{3}$ at +25 
${ }^{\circ} \mathrm{C}$ (stirred slurry); [h] $\left(\mathrm{H}_{9} \mathrm{C}_{4}\right)_{4} \mathrm{NF}$ hydrate in THF at $+25{ }^{\circ} \mathrm{C}$.

In the preceding four paragraphs several chlorofluoropyridylmetals are mentioned which contain the two lightest halogen elements simultaneously and wherein the metal resides at a chlorine-adjacent position (3-chloro-2-fluoropyrid-4-yllithium, 4,5-dichloro-6fluoropyrid-3-yllithium, 4-chloro-5-fluoropyrid-3-yllithium, 4-chloro-5,6-difluoropyrid-3yllithium and 4-chloro-2,6-difluoropyrid-3-ylpotassium/lithium). To this list 3,5-dichloro-2fluoropyrid-4-yllithium, ${ }^{[63]}$ 5-chloro-2,3-difluoropyrid-4-yllithium ${ }^{[63]}$ and 3-chloro-5fluoropyrid-4-yllithium ${ }^{[62]}$ may be added.

The first three out of six possible trifluoropyridyllithiums have been described recently: 4,5,6-trifluoropyrid-3-yllithium ${ }^{[62]}(\mathbf{3 7 b})$ and 2,4,6-trifluoropyrid-3-yllithium ${ }^{[59]}$ (37c). Two of the three possible tetrafluoropyridyllithiums are known: 2,3,4,6tetrafluoropyrid-3-yllithium ${ }^{[59,65]} \quad$ (38a) and 2,3,5,6-tetrafluoropyrid-4-yllithium ${ }^{[66]}$ (Scheme 27).

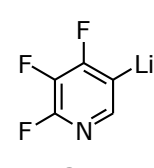

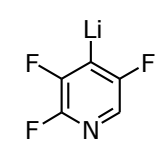

37b

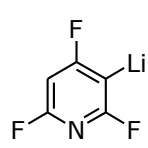

37c

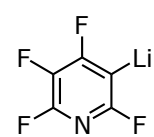

$38 \mathbf{a}$

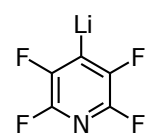

38b

Scheme 27. A few tri- and tetrafluoropyridyllithiums.

Trifluoromethyl-substituted aromatic or heterocyclic building blocks attract more and more attention. ${ }^{[67]}$ The required starting material can be readily made either by treatment of a trichloromethyl precursor with hydrogen fluoride, ${ }^{[68]}$ a suitable carboxylic acid with sulfur tetrafluoride $^{[69]}$ or by bromine or iodine displacement with in situ generated trifluoromethylcopper. ${ }^{[70]}$ If a metal can be selectively introduced into such a structure, subsequent functionalization is a mere trifle.

Ten of twelve possible (trifluoromethyl)pyridyllithiums have been set free by bromine/lithium or iodine/lithium permutation using butyllithium in tetrahydrofuran or toluene. ${ }^{[71]}$ They all proved chemically and thermally stable at temperatures around or below $-50{ }^{\circ} \mathrm{C}$. Such species can also be generated by hydrogen/metal rather than halogen /metal interconversion also the success of the metalation option depends closely on the exact 
reaction conditions. 2-(Trifluoromethyl)pyrid-3-yllithium (39a, Scheme 28) is obtained cleanly by treatment of 2-(trifluoromethyl)pyridine with LITMP in THF after 6 h. ${ }^{[72]}$ After short exposure times or in DEE inevitably regioisomeric mixtures are produced. Caubère's base in DEE metalates 2-(trifluoromethyl)pyridine effectively at the 6-position (intermediate 39b). ${ }^{[72]}$ 4-(Trifluoromethyl)pyridine can be smoothly lithiated with LITMP in THF at $-75{ }^{\circ} \mathrm{C}$ at the 3-position and with Caubère's base at the 2-position (intermediates 39c and 39d, respectively, Scheme 28 ).

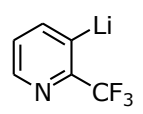

$39 a$

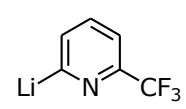

39b

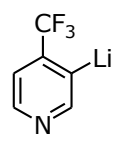

39c

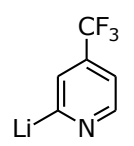

39d

Scheme 28. Several (trifluoromethyl)pyridyllithiums from 2- and 4-(trifluoromethyl)pyridine by metalation (hydrogen/metal permutation).

According to a literature report, ${ }^{[73]}$ not only 2,5-, 3,4- and 3,5bis(trifluoromethyl)pyridine but also 3-(trifluoromethyl)pyridine can be selectively metalated at the 2- (or 6-)position and subsequently trapped as the carboxylic acids in satisfactory yields $(55-85 \%)$. The repetition of some parts of this work proved frustrating. The true yield of 3(trifluoromethyl)pyridine-2-carboxylic acid (via intermediate 40, Scheme 29) reproducibly obtained by several collaborators was $1.0-1.5 \%$ rather than the claimed $75 \%$. The main component identified in the tar-like product mixture is 1-butyl-5-(difluoromethyl)pyridine, obviously formed as a consequence of nucleophilic addition of the organometallic reagent to the heterocyclic substrate (intermediate 41, Scheme 29). ${ }^{[72]}$ 3-(Trifluoromethyl)-2(trimethylsilyl)pyridine can be isolated in 30\% yield when generated under in situ trapping conditions. ${ }^{[74]}$ This compound can be readily converted by halodesilylation ${ }^{[75]}$ into 2-bromoor 2-iodo-3-(trifluoromethyl)pyridine (X = Br, I) and, although not yet attempted, presumably also by nitrodesilylation ${ }^{[76]}$ into 2-nitro-3-(trifluoromethyl)pyridine $\left(\mathrm{X}=\mathrm{NO}_{2}\right)$ and by Hiyama coupling $^{[77]}$ into 2-aryl-3-(trifluoromethyl)pyridines (X = aryl, Scheme 29). 


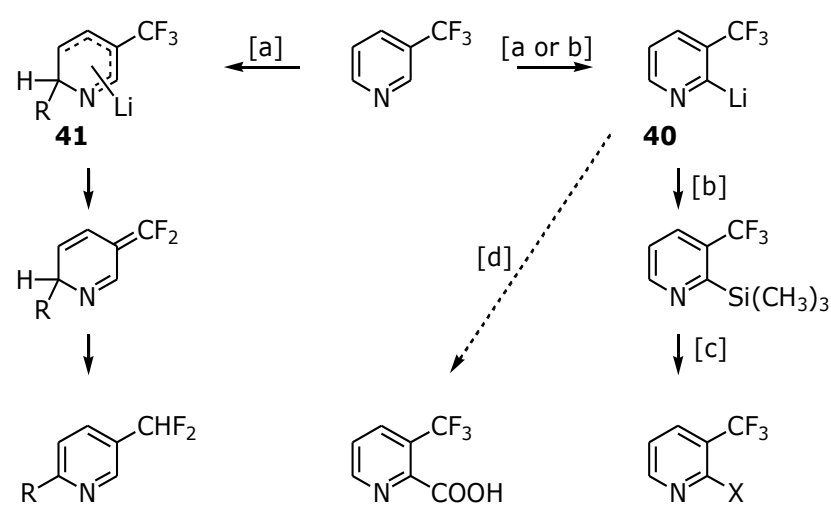

$\left[\mathrm{R}=\mathrm{H}_{9} \mathrm{C}_{4} ; \mathrm{X}=\mathrm{Br}, \mathrm{I}\right.$, etc. $]$

Scheme 29. Reaction of 3(trifluoromethyl)pyridine with strong bases: nucleophilic adition vs. deprotonation. Reaction conditions: [a] $\mathrm{LiC}_{4} \mathrm{H}_{9}$ in DEE at $-75{ }^{\circ} \mathrm{C}$. [b] LIDA and $\mathrm{ClSi}\left(\mathrm{CH}_{3}\right)_{3}$ in THF at $-75{ }^{\circ} \mathrm{C}$. [c] Heating with $\mathrm{Br}_{2}$ or ICl. [d] (1.) $\mathrm{CO}_{2}$ (2.) aq. $\mathrm{HCl}$.

The metalation/functionalization sequence can also be applied to (trifluoromethyl)pyridines carrying additional heterosubstituents. For example, when 2amino-3-chloro-5-(trifluoromethyl)pyridine was $\mathrm{N}$-pivaloyl protected and subsequently treated with two equivalents of LIDA, the resulting 4-lithiated intermediate (42, Scheme 30) reacts with iodine or benzaldehyde and, after deprotection, affords the final products in satisfactory over-all yield. ${ }^{[78]}$

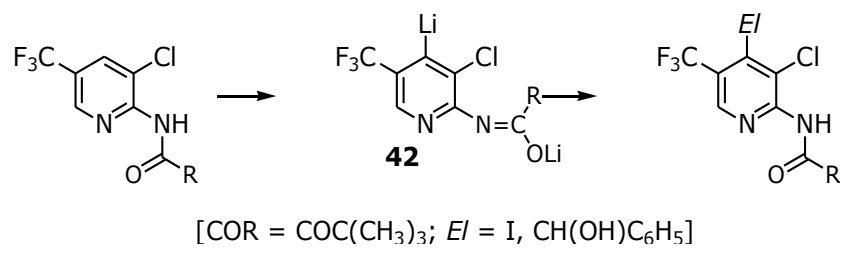

Scheme 30. Metalation and subsequent electrophilic substitution of $N$-pivaloyl protected 2-amino-3-chloro-5-(trifluoromethyl)pyridine.

The readily available ${ }^{[70,78-80]}$ chloro(trifluoromethyl)pyridine are challenging model compounds to test the scope of the methods elaborated for performing regiochemically exhaustive functionalizations. In the entire series, one site is always kinetically more acidic than the others and thus can be directly deprotonated. This is, for instance, the 4-position of 5chloro-2-(trifluoromethyl)pyridine. ${ }^{[80]}$ The corresponding derivatives can be hence obtained with minimal effort. The open question is whether or not the same set of organometallic 
methods will routinely enable the preparation of the two other isomers. As the following examples demonstrate, this is the case indeed.

Fast proton abstraction occurs again from the 4-position, when 2-chloro-5(trifluoromethyl)pyridine is treated with LIDA in the presence of lithium $N, N$ diisopropylcarbamate and lithium bromide in THF at $-75^{\circ} \mathrm{C} .{ }^{[79]}$ Reaction of the intermediate 43 with elemental iodine provides 2-chloro-4-iodo-5-(trifluoromethyl)pyridine from which the organometallic precursor species (43) can be regenerated by iodine/lithium permutation. On the other hand, the iodo compound can be subjected to a LIDA-promoted heavy halogen migration $^{[64]}$ which displaces the iodine from the 4- to the 6-position. Quenching of the lithiated intermediate $\mathbf{4 4 a}$ produces a neutral 6-iodo compound which can be converted into the corresponding carboxylic acid by halogen/metal permutation (intermediate 45a) and subsequent carboxylation. Curiously, the iodine reappears at the 3- rather than at the 6position when its migration is triggered with the "slim" lithium piperidide (LIPIP) rather than with the bulky LIDA. In this way, the 2-chloro-5-(trifluoromethyl)pyridine-3-carboxylic acid can also be readily made (via intermediates $\mathbf{4 4 b}$ and $\mathbf{4 5 b}$, Scheme 31). ${ }^{[79]}$ 2-Chloro-5(trifluoromethyl)pyridine represents an atypical case as it covers the sole example of a reagent-dependent directionally diverging heavy halogen migration known so far. In general, protective groups are required to steer the metal to the targeted location.

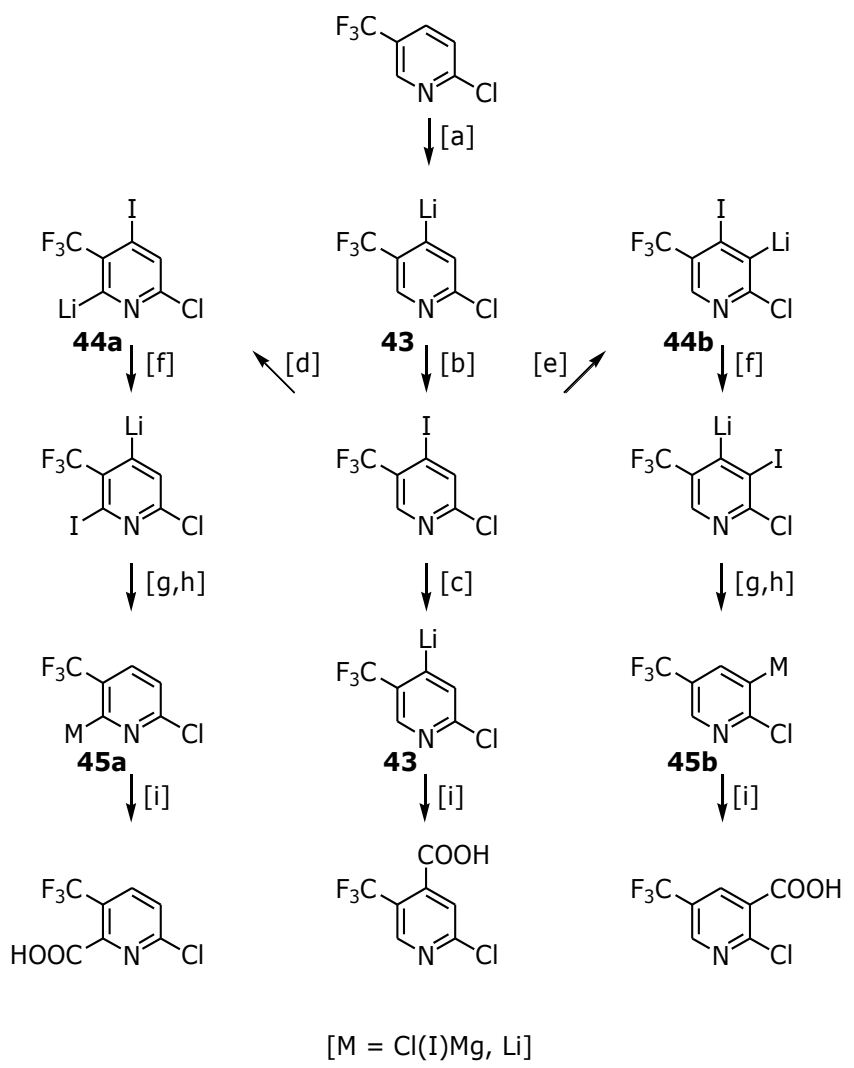


Scheme 31. Regiochemically exhaustive functionalization of 2-chloro-5(trifluoromethyl)pyridine. Reaction conditions: [a] LIDA + LiOOC-N $\left({ }^{i} \mathrm{C}_{3} \mathrm{H}_{7}\right)_{2}+\mathrm{LiBr}$ in THF at $-75{ }^{\circ} \mathrm{C}$; [b] $\mathrm{I}_{2}$; [c] $\mathrm{LiC}_{4} \mathrm{H}_{9}$ in THF at $-75{ }^{\circ} \mathrm{C}$; [d] LIDA in THF at $-75{ }^{\circ} \mathrm{C}$; [e] $\mathrm{LiN}\left(\mathrm{CH}_{2}\right)_{5}$ (LIPIP) in $\mathrm{THF}$ at $-75{ }^{\circ} \mathrm{C}$ (for $20 \mathrm{~h}$ ); [f] rapid spontaneous swap of $\mathrm{Li}$ and I places; [ $\mathrm{g}$ ] $\mathrm{H}_{2} \mathrm{O}$ or $\mathrm{HOCH}_{3}$; [h] $\mathrm{ClMgCH}\left(\mathrm{CH}_{3}\right)_{2}\left(\right.$ or $\left.\mathrm{LiC}_{4} \mathrm{H}_{9}\right)$ in THF at $-75{ }^{\circ} \mathrm{C}$; [i] (1.) $\mathrm{CO}_{2}$ (2.) aq. $\mathrm{HCl}$.

3-Chloro-4-(trifluoromethyl)pyridine is cleanly metalated at the 2-position (intermediate 46, Scheme 32). Carboxylation leads to the corresponding carboxylic acid and condensation with chlorotrimethylsilane to a 2-silylated derivative which undergoes metalation at the next acidic 5-position (intermediate 47). Carboxylation gives the second acid whereas iodination followed by deprotonation triggered heavy halogen migration, ${ }^{[64]}$ neutralization and iodine/magnesium permutation gives another organometallic intermediate $(48)^{[79]}$ which opens the entry to the last missing carboxylic acid (Scheme 32).

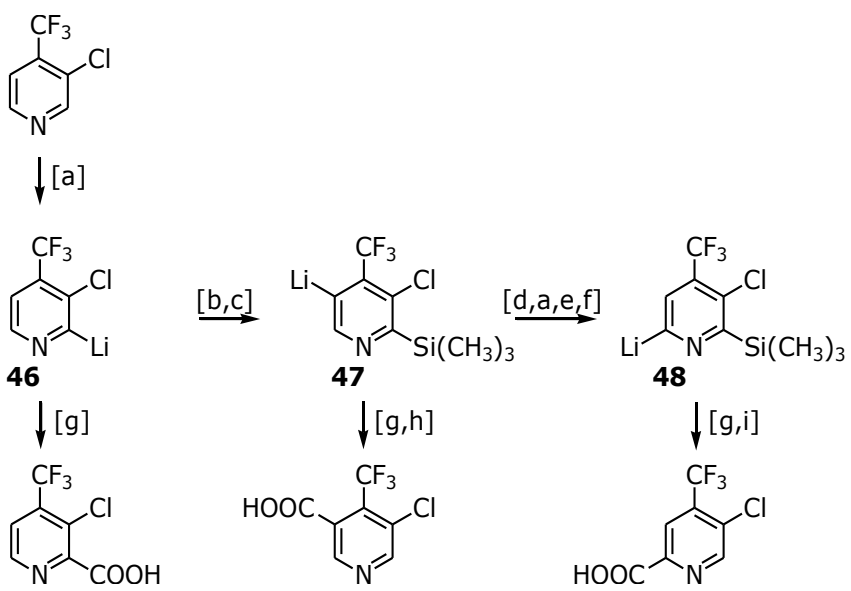

Scheme 32. Regiochemically exhaustive functionalization of 3-chloro-4-(trifluoromethyl)pyridine. Reaction conditions: [a] LITMP in DEE at $-100{ }^{\circ} \mathrm{C}$; [b] $\mathrm{ClSi}\left(\mathrm{CH}_{3}\right)_{3}$; [c] LITMP in THF at $-75{ }^{\circ} \mathrm{C}$; [d] $\mathrm{I}_{2}$; [e] $\mathrm{H}_{2} \mathrm{O}$ or $\mathrm{HOCH}_{3}$ or acid; [f] $\mathrm{LiC}_{4} \mathrm{H}_{9}$ in toluene at $-75{ }^{\circ} \mathrm{C}$; [g] (1.) $\mathrm{CO}_{2}$ (2.) aq. $\mathrm{HCl}$; [h] (1.) aq. sodium hydroxide at $100{ }^{\circ} \mathrm{C}$ (2.) aq. $\mathrm{HCl}$; [i] $\left(\mathrm{H}_{9} \mathrm{C}_{4}\right)_{4} \mathrm{NF}$ hydrate in refluxing THF.

Alkyllithium or lithium dialkylamide bases attack 3-chloro-2-(trifluoromethyl)pyridine at the 4-position, as expected. Iodination of the intermediate 49a followed by deprotonationtriggered heavy halogen migration, neutralization and iodine/metal permutation (using isopropylmagnesium chloride) produces an organometallic species $49 \mathbf{b}$. Caubère's base 
metalates 3-chloro-2-(trifluoromethyl)pyridine at the 6- (rather than the 4-)position, thus giving rise to species 49c. Standard carboxylation and ultimate neutralization transforms the intermediates 49 into the three corresponding pyridinecarboxylic acids (Scheme 33). ${ }^{[78]}$

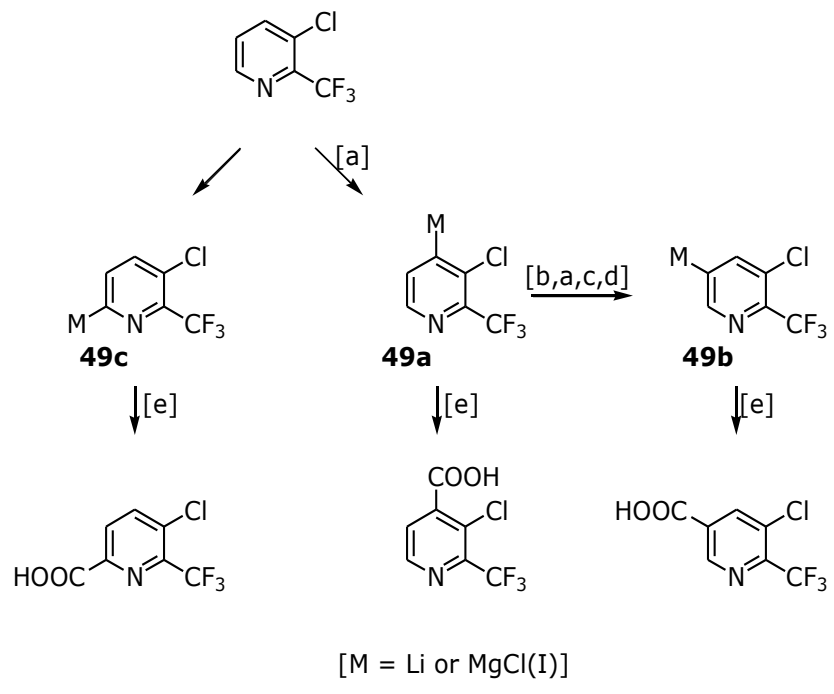

Scheme 33. Regiochemically exhaustive functionalization of 3-chloro-2-(trifluoromethyl)pyridine. Reaction conditions: [a] LIDA in THF at $\quad-75 \quad{ }^{\circ} \mathrm{C} ; \quad[\mathrm{b}] \quad \mathrm{I}_{2} ; \quad[\mathrm{c}] \quad \mathrm{HOCH}_{3} ; \quad[\mathrm{d}]$ $\mathrm{ClMgCH}\left(\mathrm{CH}_{3}\right)_{2}$ in $\mathrm{THF}$ at $0{ }^{\circ} \mathrm{C}$; [e] (1.) $\mathrm{CO}_{2}$ (2.) aq. $\mathrm{HCl}$.

2-Chloro-6-(trifluoromethyl)pyridine itself undergoes metalation at the 3-position (intermediate 50, Scheme 34) but at the 5-position (intermediate 51), when the 3-position is occupied by a trialkylsilyl protective group. The third precursor to the targeted pyridinecarboxylic acids is obtained after lithiation and iodination at the 3-position by deprotonation-triggered displacement of the heavy halogen atom to the 4-position in exchange against lithium (intermediate 53) followed by neutralization and halogen/metal permutation using lithium tributylmagnesate ${ }^{[81]}$ (Scheme 34). ${ }^{[79]}$

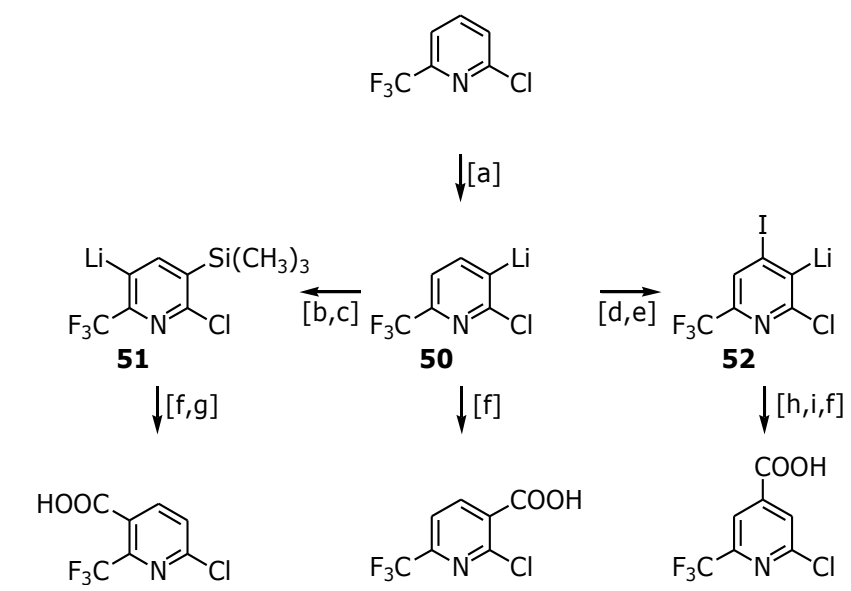


Scheme 34. Regioexhaustive functionalization of 2-chloro-6-(trifluoromethyl)pyridine. Reaction conditions: [a] LIDA in THF at $-85(!){ }^{\circ} \mathrm{C}$; [b] $\mathrm{ClSi}\left(\mathrm{CH}_{3}\right)_{3}$; [c] LITMP in THF at $-75{ }^{\circ} \mathrm{C}$; [d] $\mathrm{I}_{2}$; [e] LIDA in THF at $-75^{\circ} \mathrm{C}$; [f] (1.) $\mathrm{CO}_{2}$ (2.) aq. $\mathrm{HCl} ;[\mathrm{g}]\left(\mathrm{H}_{9} \mathrm{C}_{4}\right)_{4} \mathrm{NF}$ hydrate in $\mathrm{THF}$ at $+25{ }^{\circ} \mathrm{C}$; [h] $\mathrm{H}_{2} \mathrm{O}$ or $\mathrm{HOCH}_{3}$ or acid; [i] $\operatorname{LiMg}\left(\mathrm{C}_{4} \mathrm{H}_{9}\right)_{3}$ (0.33 molar equivalents).

The regioexhaustive functionalization of 2-bromo-6-(trifluoromethyl)pyridine passes through virtually the same steps (Scheme 35). Direct metalation affects the 3-position but is, by silylation there, deflected to the 5-position (intermediates 53 and 54, Scheme 34). Introduction of an iodine atom at the 3-position and its basicity gradient-driven migration to the adjacent 4-position generates intermediate 55. When the 2-bromo-4-iodo-6(trifluoromethyl)pyridine formed upon neutralization is treated with isopropylmagnesium chloride in THF at $0{ }^{\circ} \mathrm{C}$, whereas the iodine atom is replaced by the metal the bromine atom is completely retained. This comparison reveals a marked discrimination of the halogen/metal permutation reaction in favor of the heaviest halogen. Iodine participates instantaneously in this process, bromine more slowly and chlorine, not to speak of fluorine, not at all.

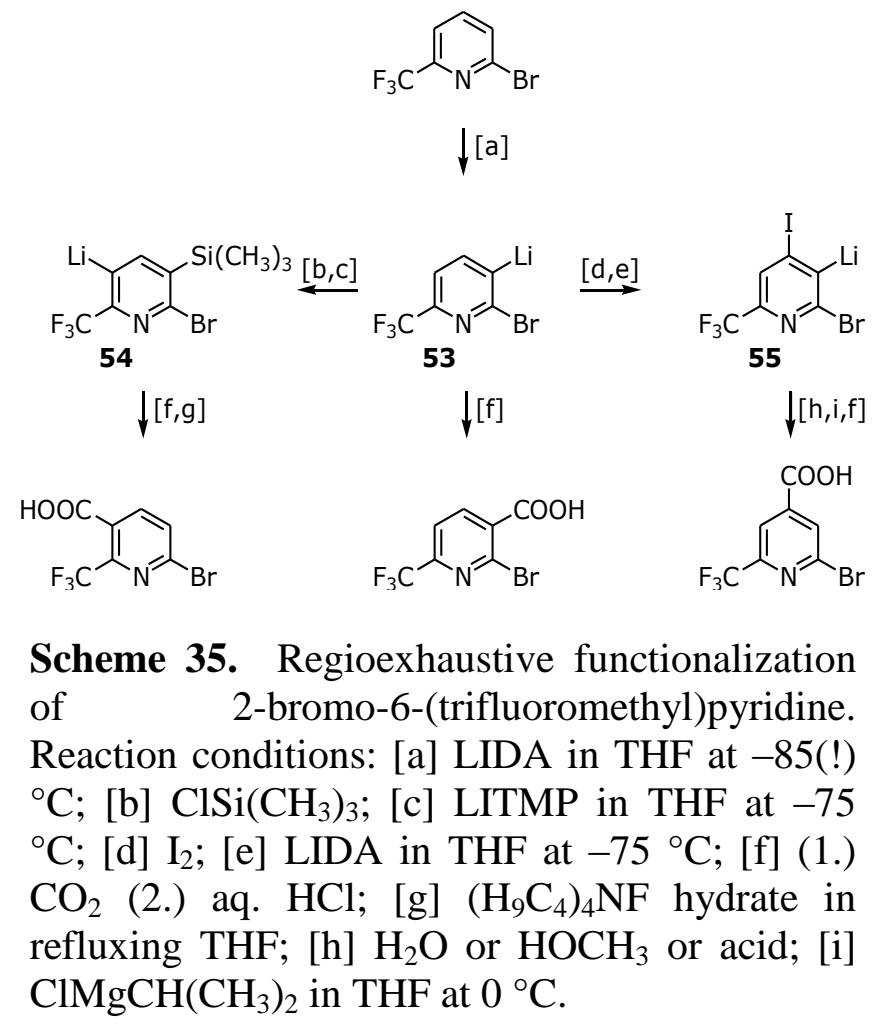

The last examples featuring halo(trifluoromethyl)pyridines (Schemes 31 - 35) demonstrate the general feasibility of regioselective functionalizations by means of the "toolbox methods". ${ }^{[12]}$ At the same time, one recognizes the remarkable thermal stability 
conferred upon pyridyllithiums by the trifluoromethyl group and an additional halogen substituent. Thus, neither 2-bromo-4-(trifluoromethyl)pyrid-3-yllithium (56a) nor 5-bromo-2(trifluoromethyl)pyrid-4-yllithium (56b) and not even 2-iodo-4-(trifluoromethyl)pyrid-3yllithium (57a) nor 4-iodo-2-(trifluoromethyl)pyrid-3-yllithium (57b) are prone to the $\beta$ elimination of, respectively, lithium bromide or lithium iodide when kept at $-75{ }^{\circ} \mathrm{C}$ for prolonged periods of time.

\section{Summary and Outlook}

The methods outlined above enable the effortless and regiochemically exhaustive functionalization of heterosubstituted pyridines (Scheme 36) and hence open an entry to a great variety of attractive building blocks for research and development in the life sciences arena. This potential is particularly appealing when fluorine-bearing pyridine derivatives are targeted as the smallest halogen is a unique tool to engineer and fine-tune biological properties. $^{[81]}$

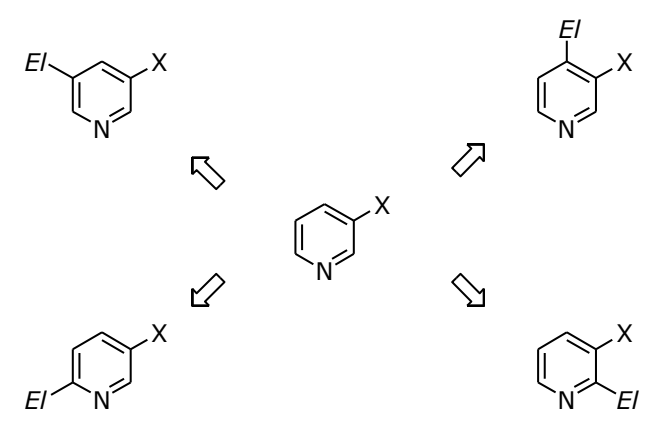

Scheme 36. Regiochemically exhaustive substitution of, for example, a 3heterosubstituted pyridine.

Despite all the impressive applications so far featured, we should not ignore inherent problems. The metalation of pyridines is a tightrope walk. Pyridine is more acidic than benzene by $10 \mathrm{kcal} / \mathrm{mol}$ in the gas phase ${ }^{[82]}$ and, based on rate estimates regarding the basecatalyzed hydrogen isotope exchange, by some $7.6 \mathrm{kcal} / \mathrm{mol}$ in the condensed phase ${ }^{[83,84]}$. The kinetics reflect such differences in thermodynamics. 2-Fluoropyridine is metalated by secbutyllithium or LITMP in tetrahydrofuran at $-75{ }^{\circ} \mathrm{C}$, after statistical correction, 720 or, respectively, 520 times faster than benzene ${ }^{[85]}$. At the same time the proneness of the substrate to undergo nucleophilic additions or substitutions increases steeply when a benzenic derivative is replaced by a pyridinic one. It requires skills and cleverly selected working conditions to maneuver successfully between the desired and undesired reaction mode. 
If adequate precautions are taken, the organometallic approach to structure elaboration offers singular advantages. The possibility to attach substituents, in particular functionality, selectively to any vacant position ("regiochemical exhaustiveness" ${ }^{[12,56]}$ ) has already been mentioned above. Product flexibility is another inestimable virtue. The metal present in the reaction intermediate may be replaced by any electrophilic component, carbon dioxide, the popular trapping agent, being just one out of hundreds if not thousands of candidates. Finally, organometallic reactions use to proceed rapidly and often quantitatively. This is an invitation to realize shortcuts in synthesis sequences and to contract several individual steps to a one-pot protocol. ${ }^{[86]}$

Traditionally pyridines play a privileged role in the realm of heterocycles. Therefore, they were in the focus of the present article. However, the concepts and methods described can be of course applied to other six- or five-membered $N$-heterocycles or $O$ - and $S$-heterocycles as well.

\section{Acknowledgment}

Financial support was provided by the Schweizerische Nationalfonds zur Förderung der wissenschaftlichen Forschung (grant 20-63'584-00), the Bundesamt für Berufsbildung und Technologie (KTI-Projekt 5474.1 KTS) and the Bundesamt für Bildung und Wissenschaft (grant 97.0083 linked to the TMR project FMRXCT-970129; grant C02.0060 linked to a COST D24 project).

\section{References}

[1] J. A. Joule, K. Mills, G. F. Smith, Heterocyclic Chemistry, $3^{\text {rd }}$ edition, Stanley Thornes, Cheltenham (UK), 1998, pp. 77 - 81.

[2] K. Ziegler, H. Zeiser, Ber. Dtsch. Chem. Ges. 1930, 63, 1847- 1851.

[3] (a) K. Akiba, Y. Iseki, M. Wada, Tetrahedron Lett. 1982, 23, 3935 - 3936; (b) K. Akiba, Y. Iseki, M. Wada, Bull. Chem. Soc. Jpn. 1984, 57, 1994 - 1999. 
[4] (a) E. Ochiai, J. Org. Chem. 1953, 18, 534 - 551; (b) H. J. den Hertog, M. van Ammers, S. Shukking, Recl. Trav. Chim. Pays-Bas 1955, 74, 1171 - 1178; (c) E. C. Taylor, A. J. Crovetti, Org. Synth., Coll. Vol. 1963, 4, 654 - 656; (d) C. D. Johnson, A. R. Katritzky, N. Shakir, M. Viney, J. Chem. Soc. B 1967, 1213 - 1219.

[5] (a) J. A. Berson, T. Cohen, J. Org. Chem. 1955, 20, 1461 - 1468; (b) R. Leonard, A. Wajngurt, J. Org. Chem. 1956, 21, 1077 - 1081; (c) A. R. Katritzky, A. M. Monro, J. Chem. Soc. 1958, 1263 - 1266; (d) but see also: E. S. Hand, W. W. Paudler, J. Heterocycl. Chem. 1975, 12, 1063 - 1064.

[6] (a) A. Kirpal, W. Böhm, Ber. Dtsch. Chem. Ges. 1931, 64, 767; (b) A. Kirpal, W. Böhm, Ber. Dtsch. Chem. Ges. 1932, 65, $680-682$.

[7] A. R. Katritzky, H. O. Tarham, S. Tarhan, J. Chem. Soc. B 1970, $114-117$.

[8] (a) H. J. den Hertog, J. P. Wibaut, Recl. Trav. Chim. Pays-Bas 1932, 51, 940 - 950;

(b) H. J. den Hertog, P. Bruin, Recl. Trav. Chim. Pays-Bas 1946, 65, 385 - 391.

[9] (a) J. Overhoff, W. Proost, Recl. Trav. Chim. Pays-Bas 1938, 57, 179 - 184; (b) J. P. Wibaut, H. G. P. van der Voort, Recl. Trav. Chim. Pays-Bas 1952, 71, 798 - 804; (c) J. P. Wibaut, R. Huls, Recl. Trav. Chim. Pays-Bas 1952, 71, 1021 - 1026; (d) J. P. Wibaut, L. G. Heeringa, Recl. Trav. Chim. Pays-Bas 1955, 74, 1003 - 1020; (e) H. Normant, Bull. Soc. Chim. Fr. 1957, $728-733$.

[10] (a) N. Furukawa, T. Shibutani, H. Fujihara, Tetrahedron Lett. 1987, 28, 5845 - 5848;

(b) F. Trécourt, G. Breton, V. Bonnet, F. Mongin, F. Marsais, G. Quéguiner, Tetrahedron Lett. 1999, 40, 4339 - 4342; (c) M. Abarbri, F. Dehmel, P. Knochel, Tetrahedron Lett. 1999, 40, 7449 - 7453.

[11] (a) J. P. Wibaut, A. P. de Jonge, H. G. P. van der Voort, P. P. H. L. Otto, Recl. Trav. Chim. Pays-Bas 1951, 70, 1054 - 1066; (b) H. E. French, K. Sears, J. Am. Chem. Soc. 1951, 73, 469 - 470; (c) H. Gilman, S. M. Spatz, J. Org. Chem. 1951, 16, 1485 1494; (d) M. Ishikura, T. Mano, I. Oda, M. Terashima, Heterocycles 1984, 22, 2471 2474; (e) A. S. Bell, D. A. Roberts, K. S. Ruddock, Synthesis 1987, 843 - 844.

[12] M. Schlosser, Angew. Chem. 2005, 116, 380 - 398; Angew. Chem. Int. Ed. 2005, 44, $376-393$

[13] M. Mallet, G. Quéguiner, Tetrahedron 1985, 41, 3433 - 3440.

[14] (a) J. Verbeek, A. V. E. George, R. L. P. de Jong, L. Brandsma, J. Chem. Soc., Chem. Commun. 1984, 257 - 258; (b) J. Verbeek, L. Brandsma, J. Org. Chem. 1984, 49, $3857-3859$. 
[15] (a) M. Schlosser, J. Organomet. Chem. 1967, 8, 9 - 16; (b) M. Schlosser, J. Hartmann, Angew. Chem. 1973, 85, 544 - 545; Angew. Chem. Int. Ed. 1973, 12, 508 - 509; (c) M. Schlosser, S. Strunk, Tetrahedron Lett. 1984, 741 - 744.

[16] (a) M. Schlosser, Pure Appl. Chem. 1988, 60, 1627 - 1634; (b) M. Schlosser, Mod. Synth. Meth. 1992, 6, 227 - 271; (c) M. Schlosser, F. Faigl, L. Franzini, H. Geneste, G. Katsoulos, G.-f. Zhong, Pure Appl. Chem. 1994, 66, 1439 - 1446.

[17] A. J. Clarke, S. McNamara, O. Meth-Cohn, Tetrahedron Lett. 1974, 15, 2373 - 2376.

[18] J. A. Zoltewicz, C. D. Dill, Tetrahedron 1996, 52, 14469 - 14474.

[19] (a) P. Caubère, Chem. Rev. 1993, 93, 2317 - 2334; (b) P. Gros, Y. Fort, G. Quéguiner, P. Caubère, Tetrahedron Lett. 1995, 4791 - 4794; (c) P. Gros, Y. Fort, P. Caubère, J. Chem. Soc., Perkin Trans. 1 1997, 3071 - 3080; (d) P. Gros, Y. Fort, P. Caubère, J. Chem. Soc., Perkin Trans. 1 1997, 3597 - 3600; (e) P. Gros, Y. Fort, P. Caubère, J. Chem. Soc., Perkin Trans. 1 1998, 1685 - 1689; (f) P. Gros, C. Viney, Y. Fort, Synlett 2002, 628 - 630; (g) P. Gros, Y. Fort, Eur. J. Org. Chem. 2002, 3375 - 3383; (h) T. Kamienski, P. Gros, Y. Fort, Eur. J. Org. Chem. 2003, 3855 - 3860.

[20] (a) R. A. Abramovitch, M. Saha, E. M. Smith, R. T. Coutts, J. Am. Chem. Soc. 1967, 89, 1537 - 1538; (b) R. A. Abramovitch, E. M. Smith, E. E. Knaus, M. Saha, J. Org. Chem. 1972, 37, 1690 - 1696; (c) R. A. Abramovitch, E. E. Knaus, J. Heterocycl. Chem. 1975, 12, 683 - 690; (d) R. A. Abramovitch, R. T. Coutts, E. M. Smith, J. Org. Chem. 1972, 37, $3584-3587$.

[21] S. L. Taylor, D. Y. Lee, J. C. Martin, J. Org. Chem. 1983, 48, 4156 - 4158.

[22] (a) S. V. Kessar, P. Singh, K. N. Singh, M. Dutt, J. Chem. Soc., Chem. Commun. 1991, 570 - 571; (b) S. V. Kessar, P. Singh, Chem. Rev. 1997, 97, 721 - 737.

[23] E. Vedejs, X. Chen, J. Am. Chem. Soc. 1996, 118, 1809-1810.

[24] Y. Kondo, M. Shilai, M. Uchiyama, T. Sakamoto, J. Am. Chem. Soc. 1999, 121, 3539 -3540 .

[25] M. Ferles, A. Šilhánková, Collect. Czechoslov. Chem. Commun. 1979, 44, 3137 3140 .

[26] (a) F. Mongin, F. Trécourt, G. Quéguiner, Tetrahedron Lett. 1999, 40, 5483 - 5486;

(b) J. Lazaar, A.-S. Rebstock, F. Mongin, A. Godard, F. Trécourt, F. Marsais, G. Quéguiner, Tetrahedron 2002, 58, 6723-6728.

[27] (a) A. R. Katritzky, S. Rahimi-Rastgoo, N. K. Ponkshe, Synthesis 1981, 127 - 129; (b) J. Epsztajn, A. Bieniek, M. W. Płotka, K. Suwald, Tetrahedron 1989, 23, 7469 - 7476.

[28] W. H. Puterbaugh, C. R. Hauser, J. Org. Chem. 1964, 29, 853 - 856.

[29] P. Beak, R. A. Brown, J. Org. Chem. 1977, 42, 1823 - 1824. 
[30] (a) J. Epsztajn, Z. Berski, J. Z. Brzeziński, A. Jóźwiak, Tetrahedron Lett. 1980, 21, 4739 - 4742; (b) M. Iwao, T. Kuraishi, Tetrahedron Lett. 1983, 24, 2649 - 2652; (c) M. Watanabe, E. Shinoda, Y. Shimizu, S. Furukawa, M. Iwao, T. Kuraishi, Tetrahedron 1987, 43, 5281 - 5286; (d) V. Bolitt, C. Mioskowski, S. P. Reddy, J. R. Falck, Synthesis 1988, 388 - 389; (e) F. Guillier, F. Nivoliers, J. Bourguignon, G. Dupas, F. Marsais, A. Godard, G. Quéguiner, Tetrahedron Lett. 1992, 33, 7355 7356.

[31] (a) H.W. Gschwend, A. Hamdan, J. Org. Chem. 1975, 40, 2008 - 2009; (b) L. DellaVecchia, I. Vlattas, J. Org. Chem. 1977, 42, 2649 - 2650.

[32] (a) A. I. Meyers, R. A. Gabel, Tetrahedron Lett. 1978, 19, 227 - 230; (b) A. I. Meyers, R. A. Gabel, J. Org. Chem. 1982, 47, 2633 - 2637; (c) E. Bisagni, M. Rautureau, Synthesis 1987, 142 - 145 .

[33] J. M. Muchowski, M. C. Venuti, J. Org. Chem. 1980, 45, 4798 - 4801.

[34] (a) T. Güngor, F. Marsais, G. Quéguiner, Synthesis 1982, 499 - 500; (b) J. A. Turner, J. Org. Chem. 1983, 48, 3401 - 3408; (c) Y. Tamura, M. Fujita, L.-C. Chen, M. Inoue, Y. Kita, J. Org. Chem. 1981, 46, $3564-3567$.

[35] (a) J. N. Reed, J. Rotchford, D. Strickland, Tetrahedron Lett. 1988, 29, 5725 - 5728; (b) V. Pomel, J. C. Rovera, A. Godard, F. Marsais, G. Quéguiner, J. Heterocycl. Chem. 1996, 33, 1995 - 2005; (c) C. Y. Fiakpui, E. E. Knaus, Can. J. Chem. 1987, 65, 1158 - 1161; (d) M. C. Venuti, R. A. Stephenson, R. Alvarez, J. J. Bruno, A. M. Strosberg, J. Med. Chem. 1988, 31, 2136 - 2145; (e) D. Hands, B. Bishop, M. Cameron, J. S. Edwards, I. F. Cottrell, S. H. B. Wright, Synthesis 1996, 877 - 882; (f) J. I. Ubeda, M. Villacampa, C. Avendaño, Synlett 1997, 285 - 286; (g) R. Crous, C. Dwyer, C. W. Holzapfel, Heterocycles 1999, 51, 721 - 726.

[36] (a) F. C. Février, E. D. Smith, D. L. Comins, Org. Lett. 2005, 7, 5457 - 5460; (b) F. F. Wagner, D. L. Comins, Eur. J. Org. Chem. 2006, 3562 - 3565.

[37] (a) F. Marsais, G. Le Nard, G. Quéguiner, Synthesis 1982, 235 - 237; (b) F. Trécourt, M. Mallet, F. Marsais, G. Quéguiner, J. Org. Chem. 1988, 53, 1367 - 1371; (c) D. L. Comins, L. A. Morgan, Tetrahedron Lett. 1991, 32, 5919 - 5922; (d) F. Trécourt, M. Mallet, O. Mongin, B. Gervais, G. Quéguiner, Tetrahedron 1993, 49, 8373 - 8380; (e) A. S. C. Chan, C.-C. Chen, R. Cao, M.-R. Lee, S.-M. Peng, G. H. Lee, Organometallics 1997, 16, 3469 - 3473.

[38] E. W. Thomas, J. Org. Chem. 1986, 51, 2184-2191.

[39] (a) M. R. Winkle, R. C. Ronald, J. Org. Chem. 1982, 47, 2101 - 2108; (b) R. C. Ronald, M. R. Winkle, Tetrahedron 1983, 39, 2031 - 2042. 
[40] L. Barsky, H. W. Gschwend, J. McKenna, H.R. Rodriguez, J. Org. Chem. 1976, 41, $3651-.3652$

[41] (a) D. L. Comins, M. O. Killpack, J. Org. Chem. 1990, 55, 69 - 73; (b) D. L. Comins, Synlett 1992, $615-625$.

[42] (a) G. W. Gribble, M. G. Saulnier, Tetrahedron Lett. 1980, 21, 4137 - 4140; (b) G. W. Gribble, M. G. Saulnier, Heterocycles 1993, 35, 151 - 169.

[43] (a) F. Marsais, P. Bréant, A. Ginguène, G. Quéguiner, J. Organomet. Chem. 1981, 216, 139 - 147; (b) F. Marsais, B. Laperdrix, T. Güngör, M. Mallet, G. Quéguiner, J. Chem. Res., Synop. 1982, 278 - 279; (c) M. Mallet, G. Quéguiner, Tetrahedron 1982, $38,3035-3042$.

[44] Y. G. Gu, E. K. Bayburt, Tetrahedron Lett. 1996, 37, 2565 - 2568.

[45] F. Effenberger, W. Daub, Chem. Ber. 1991, 124, 2119 - 2125.

[46] (a) S. Choppin, P. Gros, Y. Fort, Org. Lett. 2000, 2, 803 - 805; (b) S. Choppin, P. Gros, Y. Fort, Eur. J. Org. Chem. 2001, 603 - 606.

[47] (a) G. Katsoulos, S. Takagishi, M. Schlosser, Synlett 1991, 731 - 732; (b) F. Mongin, R. Maggi, M. Schlosser, Chimia 1996, 50, 650 - 652; (c) R. Maggi, M. Schlosser, J. Org. Chem. 1996, 61, $5430-5434$.

[48] E. Marzi, A. Bigi, M. Schlosser, Eur. J. Org. Chem. 2001, 1371 - 1376.

[49] R. Radinov, M. Haimova, E. Simova, Synthesis 1986, 886 - 891.

[50] (a) A. D. Cale, T. W. Gero, K. R. Walker, Y. S. Lo, W. J. Welstead, L. W. Jaques, A. F. Johnson, C. A. Leonard, J. C. Nolan, D. N. Johnson, J. Med. Chem. 1989, 32, 2178 -2199, spec. 2198.

[51] R. Radinov, C. Chanev, M. Heimova, J. Org. Chem. 1991, 56, 4793 - 4796.

[52] N. J. Foulger, B. J. Wakefield, J. Organomet. Chem. 1974, 69, 161 - 167.

[53] (a) L. Estel, F. Marsais, G. Quéguiner, J. Org. Chem. 1988, 53, 2740 - 2744; (b) G.-q. Shi, S. Takagishi, M. Schlosser, Tetrahedron 1994, 50, 1129 - 1134.

[54] F. Marsais, F. Trécourt, P. Bréant, G. Quéguiner, J. Heterocycl. Chem. 1988, 25, 81 87.

[55] (a) F. Marsais, G. Quéguiner, Tetrahedron 1983, 39, 2009 - 2021, spec. 2014 - 2015;

(b) J.-C. Barrière, E. Bacqué, G. Puchault, Y. Quenet, C. Molherat, J. Cassayre, J.-M. Paris, Tetrahedron 1998, 54, 12859 - 12886.

[56] (a) M. Schlosser, C. Heiss, Eur. J. Org. Chem. 2003, 4618 - 4624; (b) M. Marull, M. Schlosser, Eur. J. Org. Chem. 2004, 1008 - 1013; (c) E. Marzi, J. Gorecka, M. Schlosser, Synthesis 2004, 1609 - 1618.

[57] C. Bobbio, M. Schlosser, J. Org. Chem. 2005, 70, 3039 - 3045. 
[58] E. Marzi, C. Bobbio, F. Cottet, M. Schlosser, Eur. J. Org. Chem. 2005, 2116 - 2123.

[59] (a) M. Schlosser, T. Rausis, C. Bobbio, Org. Lett. 2005, 7, 127 - 129; (b) M. Schlosser, C. Bobbio, T. Rausis, J. Org. Chem. 2005, 70, $2494-2502$.

[60] R. D. Chambers, C. W. Hall, J. Hutchinson, R. W. Millar, J. Chem. Soc., Perkin Trans. 1 1998, $1705-1713$.

[61] M. Schlosser, T. Rausis, Eur. J. Org. Chem. 2004, 1018 - 1024.

[62] C. Bobbio, T. Rausis, M. Schlosser, Chem. Eur. J. 2005, 11, 1903 - 1910.

[63] C. Bobbio, M. Schlosser, Eur. J. Org. Chem. 2001, 4533 - 4536.

[64] C. Heiss, T. Rausis, M. Schlosser, Synthesis 2005, 617 - 621.

[65] (a) R. D. Chambers, F. G. Drakesmith, W. K. R. Musgrave, J. Chem. Soc. 1965, 5045 - 5048; (b) R. D. Chambers, C. A. Heaton, J. Chem. Soc. C 1969, 1700 - 1703.

[66] P. L. Coe, A. J. Rees, J. Fluorine Chem. 2000, 101, 45 - 60.

[67] M. Schlosser, Angew. Chem. 2006, 118, 5558 - 5572; Angew. Chem. Int. Ed. 2006, $45,5432-5446$.

[68] (a) P. Osswald, F. Müller, F. Steinhäuser (IG Farben), DRP 575593, 1931; Chem. Zbl. 1933II, 609; (b) J. H. Simons, C. J. Lewis, J. Am. Chem. Soc. 1938, 60, 492 - 497; (c) O. Scherer, Angew. Chem. 1939, 52, 457 - 459; (d) U. Horn, F. Mutterer, C. D. Weis, Helv. Chim. Acta 1976, 59, 190 - 211; (e) G. A. Olah, J. T. Welch, Y. D. Vankar, M. Nojima, I. Kerekes, J. A. Olah, J. Org. Chem. 1979, 44, 3872 - 3881; (f) L. M. Yagupolskii, D. V. Fedyuk, K. I. Petko, V. I. Troitskaya, V. I. Rudyk, V. V. Rudyuk, J. Fluorine Chem. 2000, 106, 181 - 187.

[69] (a) W. R. Hasek, W. C. Smith, V. A. Engelhardt, J. Am. Chem. Soc. 1960, 82, 543 551; (b) M. S. Raasch, J. Org. Chem. 1962, 27, 1406 - 1409; (c) Y. Kobayashi, I. Kumadaki, S. Taguchi, Chem. Pharm. Bull. 1969, 17, 2335 - 2339.

[70] F. Cottet, M. Schlosser, Eur. J. Org. Chem. 2002, 327 - 330.

[71] F. Cottet, M. Marull, O. Lefebvre, M. Schlosser, Eur. J. Org. Chem. 2003, 1559 1568 .

[72] M. Schlosser, M. Marull, Eur. J. Org. Chem. 2003, 1569 - 1575.

[73] J. Porwisiak, W. Dmowski, Tetrahedron 1994, 50, 12259 - 12266.

[74] (a) T. D. Krizan, J. C. Martin, J. Am. Chem. Soc. 1983, 105, 6155 - 6157; (b) M. Schlosser, L. Guio, F. Leroux, J. Am. Chem. Soc. 2001, 123, 3822 - 3823.

[75] C. Eaborn, J. Organomet. Chem. 1975, 100, 43 - 57.

[76] (a) G. A. Olah, C. Rochin, J. Org. Chem. 1987, 52, 701 - 702; (b) P. L. Coe, A. M. Stuart, D. J. Moody, J. Fluorine Chem. 1998, 92, 27 - 32.

[77] T. Hiyama, J. Organomet. Chem. 2002, 653, 58 - 61. 
[78] F. Cottet, M. Marull, F. Mongin, D. Espinosa, M. Schlosser, Synthesis 2004, 1619 1624.

[79] F. Cottet, M. Schlosser, Eur. J. Org. Chem. 2004, 3793 - 3798.

[80] F. Cottet, M. Schlosser, Tetrahedron 2004, 60, 11869 - 11874.

[81] (a) A. M. Thayer, Chem. Eng. News 2006, 84(23), 15 - 24; (b) A. M. Thayer, Chem. Eng. News 2006, 84(23), $27-32$.

[82] (a) M. Mautner, L.W. Sieck, J. Phys. Chem. 1986, 90, 6687 - 6690; (b) M. Mautner, S. A. Kafafi, J. Am. Chem. Soc. 1988, 110, $6297-6303$.

[83] (a) A. I. Shatenstein, J. Org. Chem. 1963, 1, 155 - 201; (b) I. F. Tupitsyn, N. N. Zatspina, A. V. Kirova, Y. L. Kaminskii, A. G. Ivanensko, Reakts. Sposobn. Org. Soedin. 1973, 10, 143 - 162 [Chem. Abstr. 1973, 79, 114928v].

[84] O. A. Reutov, I. P. Beletskaya, K. P. Butin, CH-Acids, Pergamon Press, Oxford, 1978, pp. $111-112$.

[85] F. Mongin, unpublished results (2007).

[86] (a) F. Faigl, M. Schlosser, Tetrahedron Lett. 1991, 32, 3369 - 3370; (b) M. Schlosser, G.-f. Zhong, Tetrahedron Lett. 1993, 34, 5441 - 5444. 